\title{
Vascular Anomalies of the Oro-Maxillofacial Region
}

\author{
Sanjiv Nair and Sunil S. Shroff
}

\subsection{Introduction}

Vascular anomalies are lesions arising from the arterial and/ or venous and/or lymphatic circulation. These have a wide array of histological and clinical features and constitute one of the commonest congenital anomalies in infants and children [1].

In the context of iatrogenic creation of arteriovenous fistulas by phlebotomists, William Hunter in the mid-eighteenth century first described vascular anomalies. Haemangiomas and vascular malformations are different entities of vascular anomalies and this was first recognised by James Wardrop in 1818 [2]. In spite of Dr. Wardrop's work, subjective words like 'strawberry hemangioma' and 'salmon patch' were used for a long time. These terms only reflected the appearance and did not correlate clinically or histologically [2].

Anomalies presenting in different age groups with varying clinical behaviours needing different treatments were often given the same or overlapping names by clinicians. Commonly used terms are: haemangioma, arterial malformation, venous malformation, capillary malformation and lymphatic malformation.

Haemangioma (Figs. 31.1 and 31.20): Is a benign tumour of blood vessels comprising arterioles with endothelial cells, which are proliferative and hyperplastic in nature.

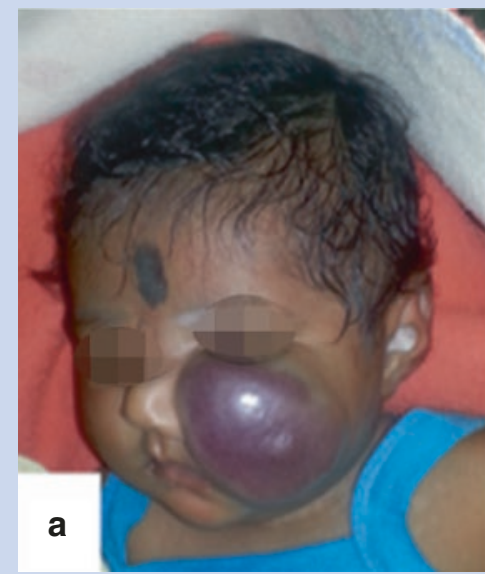

CAssociation of Oral and Maxillofacial Surgeons of India
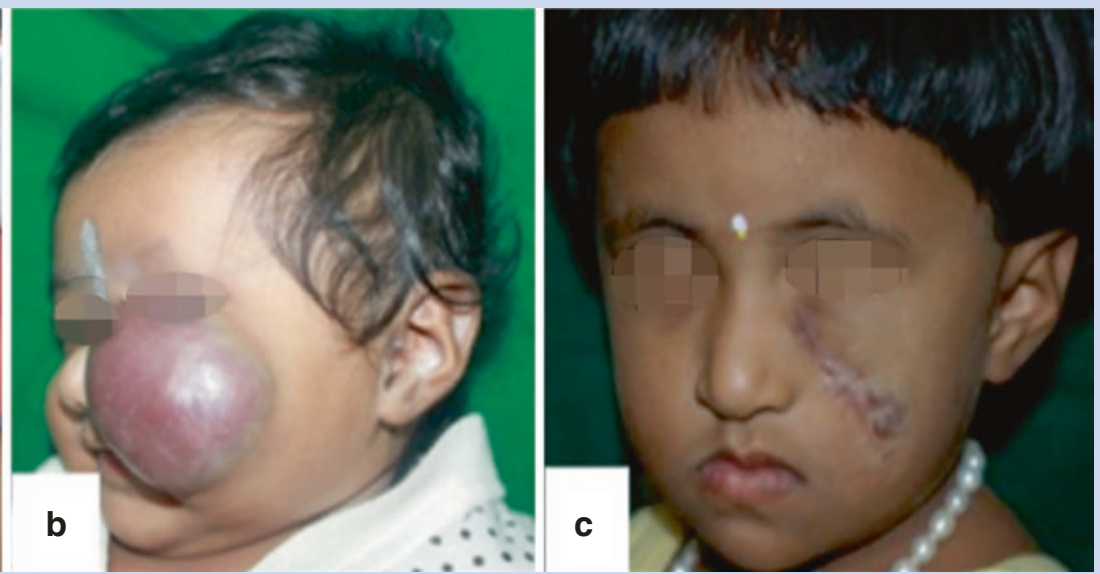

Fig. 31.1 Non-involuting congenital Haemangioma (NICH) of left cheek ((a) initial therapy with propanolol 10 days post-birth, (b) 6 months following propanolol therapy, (c) excision of lesion at 2 years age)

S. Nair $(\bowtie) \cdot$ S. S. Shroff $(\bowtie)$

Department of Oral and Maxillofacial Surgery, Bhagwan Mahaveer

Jain Hospital, Bengaluru, Karnataka, India 
This terminology has been used by many as a common term for any vascular anomaly especially in childhood. These develop within the initial few weeks of life but often resolve with time. It is necessary for one to be able to differentiate between haemangioma and other vascular anomalies.

Arterial malformation (Fig. 31.2): These are dilated, overlapping and tortuous arteries having a coil-like appearance and/or a collection of arterial loops without any venous component. They are also described as 'high flow lesions'.

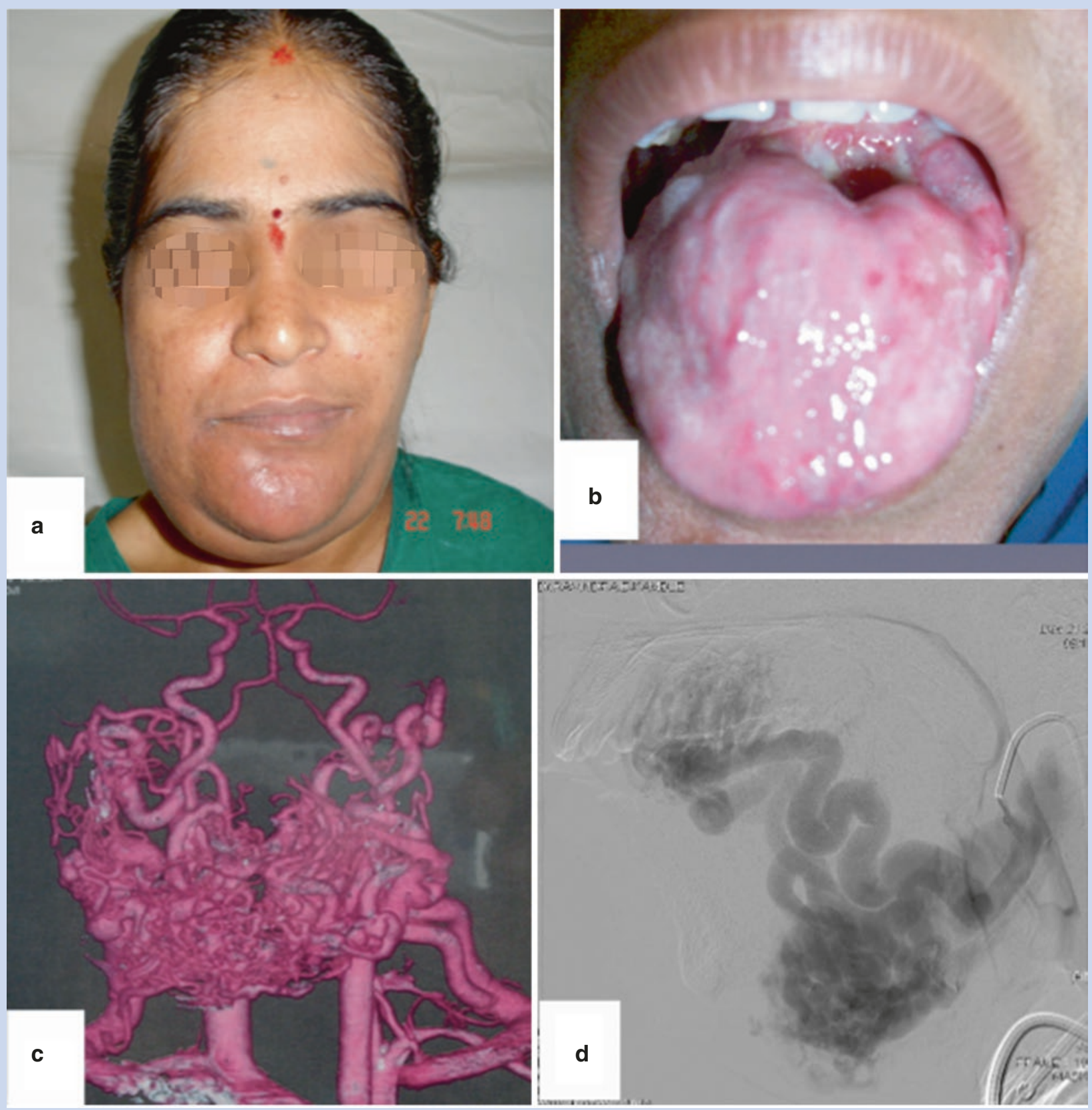

CAssociation of Oral and Maxillofacial Surgeons of India

Fig. 31.2 Arterial malformation ((a, b) tongue high flow lesion, (c) DSA, (d) embolisation) 
Venous malformation (Fig. 31.3): These are commonest type of vascular malformations caused by ectatic venous channels, also called 'low flow lesions'.
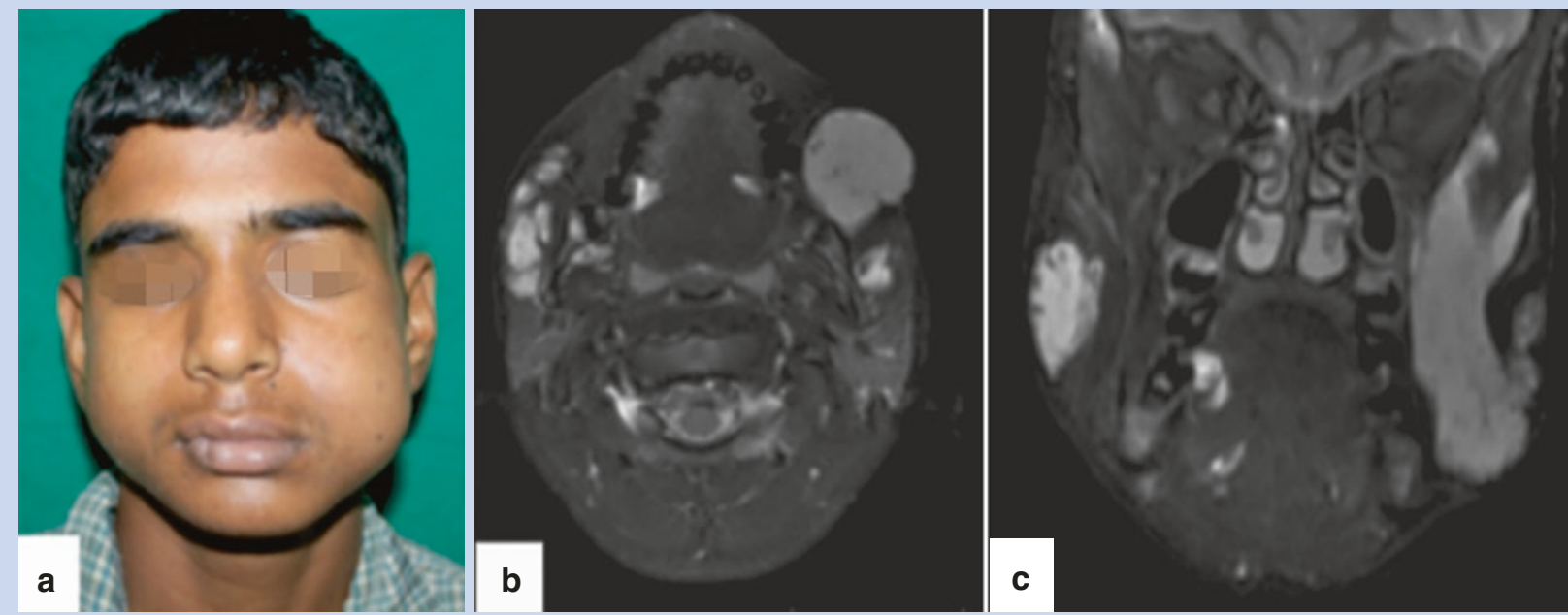

(C)Association of Oral and Maxillofacial Surgeons of India

Fig. 31.3 Left cheek venous malformation ((a) pre-operative Left cheek VM, (b) axial and (c) coronal STIR sequence MRI)

Capillary malformations (Fig. 31.4): These are commonly known as, 'port wine stain'. It is a flat, well-defined vascular stain of skin seen early in development when vessels of skin form abnormally which can increase in size and give a nodular appearance as a late presentation.

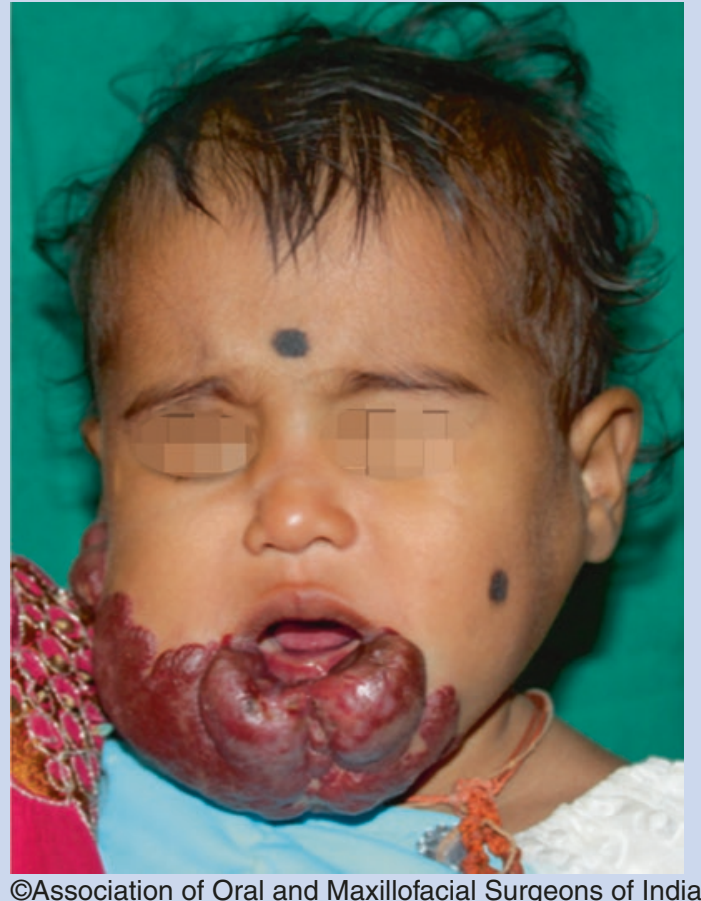

Fig. 31.4 Capillary malformation of lower lip, chin and right cheek 
Lymphatic malformation (Fig. 31.5a, b): These are lesions containing fluid-filled spaces or channels, thought to be caused by abnormal development of the lymphatic system.
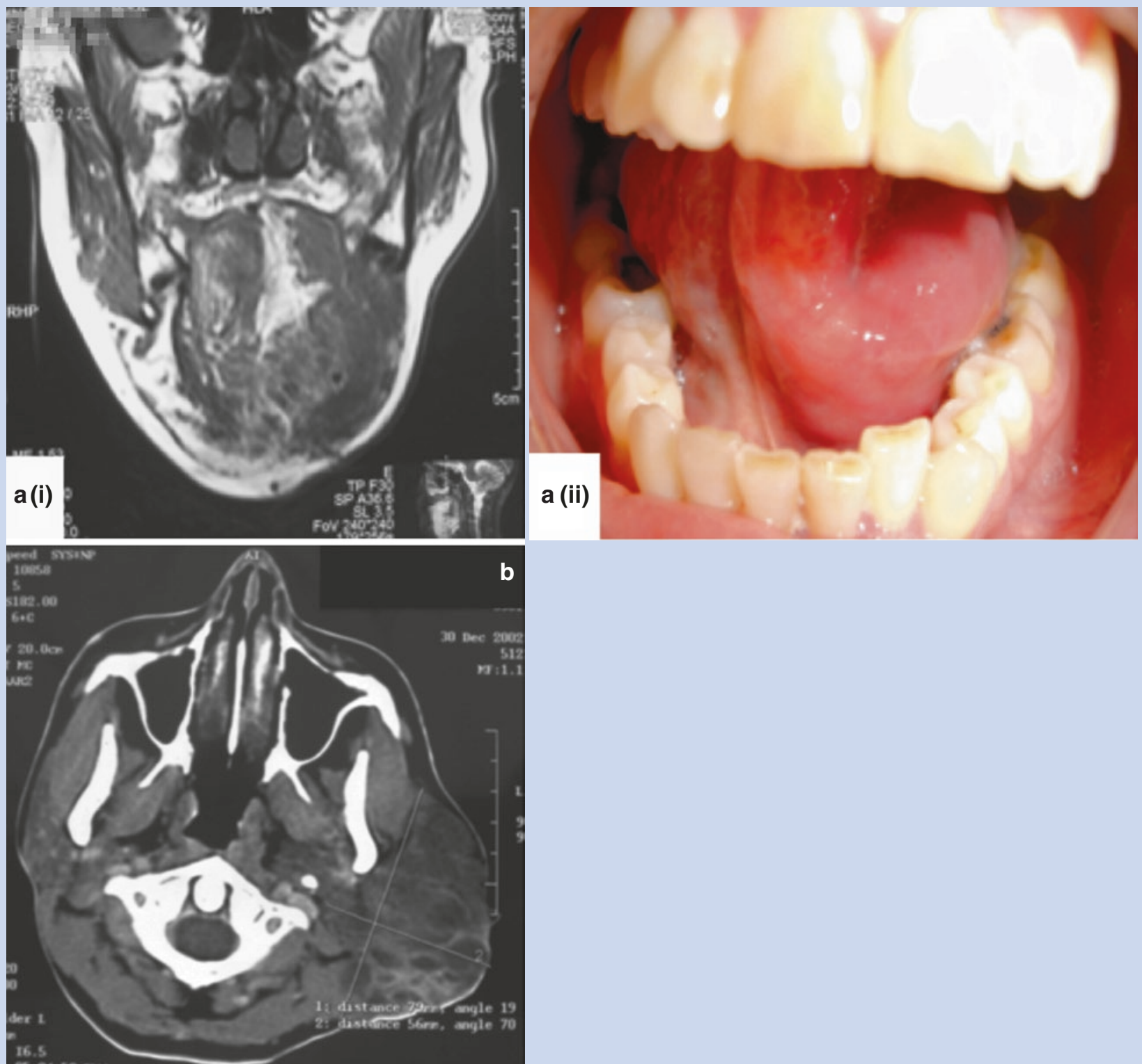

OAssociation of Oral and Maxillofacial Surgeons of India

Fig. 31.5 (a) Micro-cystic lymphatic malformation of tongue ((i) coronal T2 weighted MRI image, (ii) pre-operative clinical). (b) Axial post-contrast image of macro-cystic lymphatic malformation of left Parotid. Copyright: Authors own publication from IJOMS 2018 
The above lesions in different combinations make up for 'arteriovenous' (Fig. 31.6) and 'lymphovenous' malformations.

\subsection{Pathogenesis}

Histologically, vascular anomalies are seen as a localised increase in vasculature with abnormal tortuosity and enlargement. This is known to be caused by defects in the formation of these vessels during vasculogenesis [3].

'Vasculogenesis' is defined as growth of vessels from precursor cells like, haemangioblasts that further give rise to angioblasts and haemocytoblasts.

Fusion takes place in islands of vasculature leading to the formation of primary capillary plexus, which then extends and matures during angiogenesis. This involves the proliferation of endothelial cells and the recruitment of mural cells to form fully developed and functional lymphatic and vascular trees [4].

Angiogenesis is regulated by factors like VEGFs (vascular endothelial growth factors), FGFs (fibroblast growth factors), PDGF-beta (platelet derived growth factor beta) and ANGPT-1 and ANGPT-2 (angiopoietins). These factors cause activation of precursor cells, leading to migration, proliferation and differentiation of the primary capillary plexus [5].

VEGFs, angiopoietins, and their endothelial tyrosine kinase receptors are known to be the central regulators of vasculogenesis, angiogenesis and lymphangiogenesis [4].

Haemangiomas have currently 2 dominant theories [6], although unclear. These are:

1. Endothelial cells are formed from deranged placental tissue present in foetal soft tissues during gestation.

2. Stem cells and endothelial progenitor cells which give rise to haemangiomas, are found in circulation of patients with haemangiomas.

Abnormal levels of matrix metalloproteinases (MMP9) and proangiogenic factors (VEGF, b-FGF and TGF-beta 1) are involved in the pathogenesis of haemangioma. Genetic errors involving growth factor receptors are also known to influence the development of these lesions [6].

There are 3 stages in the life cycle of haemangiomas [7], each characterised by biological markers and processes. These stages are clinically seen and distinguished microscopically and immunohistochemically [8] as,

1. Proliferative phase-0-1 year of age

2. Involuting phase-1-5 years of age

3. Involuted phase-more than 5 years of age
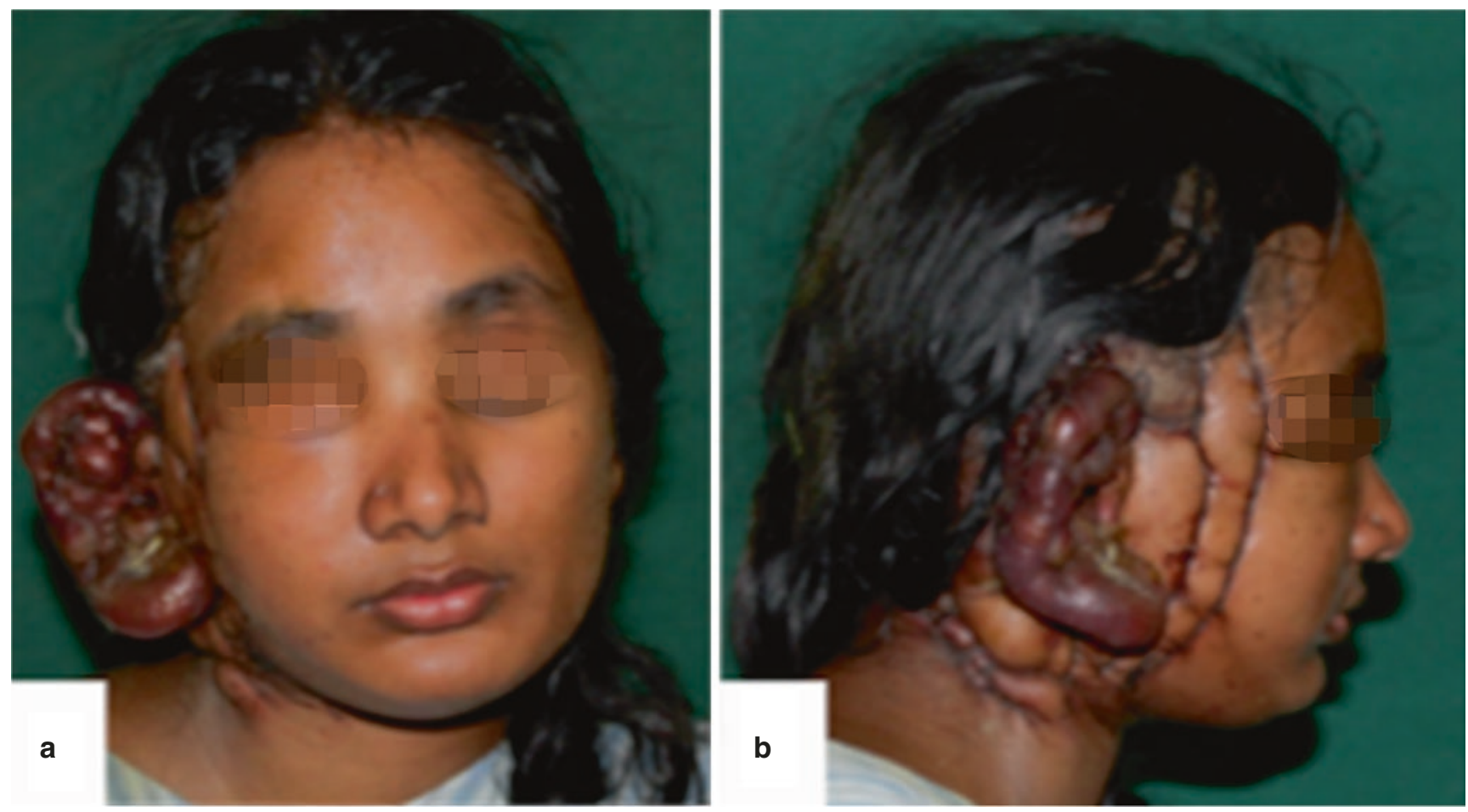

Fig. 31.6 Arteriovenous malformation of pinna of right ear ( $(\mathbf{a}, \mathbf{b})$ previous Popescu suturing as reported, (c) coronal CT angiography image, $(\mathbf{d})$ contrast MR angiography image). Copyright: Authors own publication from IJOMS 2018 


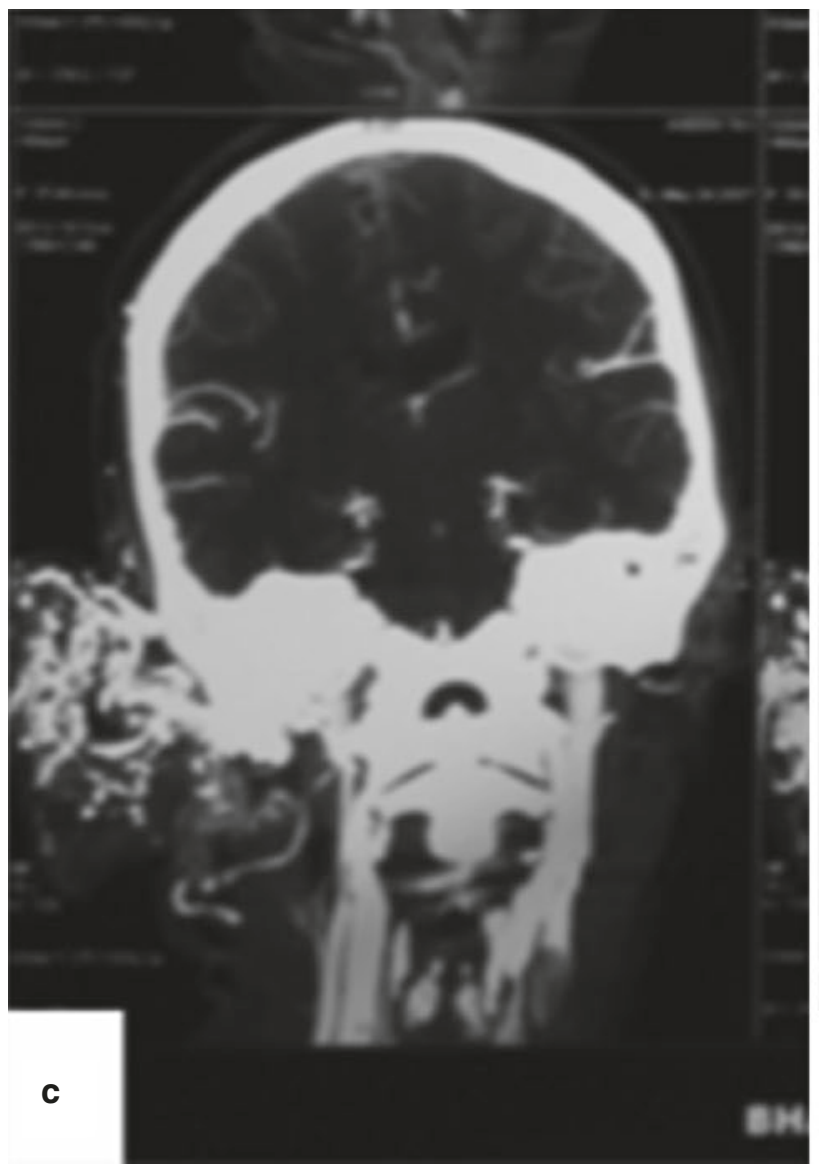

CAssociation of Oral and Maxillofacial Surgeons of India

Fig. 31.6 (continued)

Venous malformations (VMs) are known to be autosomally dominant showing high penetrance. Abnormal venous connections cause venous congestion, thrombosis and slow expansion of these lesions. VMs commonly have a sporadic occurrence, but research has suspected a genetic locus to be involved in their development [6]. Chromosome 9p has been localised to cause inherited forms of VMs. The loss of functional mutation on the angioprotein-receptor gene TIE2/TEK and upregulation of many factors like tissue growth factor beta (TGF-beta) and basic fibroblast growth factor (beta-FGF) is seen [6]. Progesterone receptors are also found in VMs, which explains their propensity to enlarge rapidly during hormonal changes.

The pathogenesis of capillary malformations $(C M s)$ is not clearly understood. These can be seen anywhere on the body, localised to a dermatome or extensive in nature. A familial pattern has been identified with a locus on chromosome $5 \mathrm{q}$ in a genome-wide linkage analysis [9].

Lymphatic malformations (LMs) show a focal pattern of occurrence. The aetiology is not clearly understood. Although most cases are congenital, there is no evidence of associated familial pattern. There have been cases of LMs following trauma or infection. Receptors like VEGFR3 and Prox-1, likely play a role in their development [10].

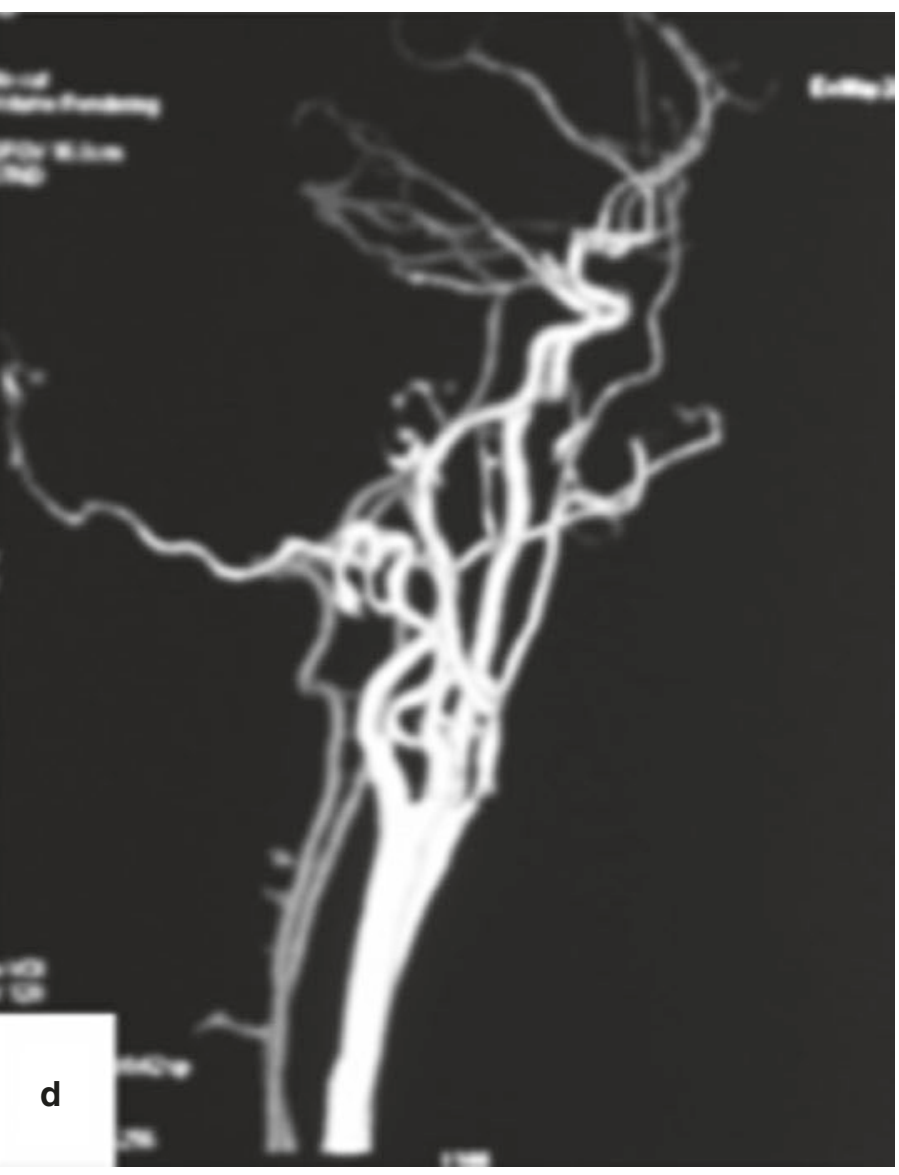

The pathogenesis of arterio-venous malformations $(A V M s)$ is also not clearly understood. A defect in vascular stabilisation is known to potentially cause AVMs. Intracranial AVM is seen most commonly, followed by AVMs involving extracranial head and neck, extremities, trunk and viscera. These are seen at birth and are frequently misdiagnosed as a CM or haemangioma. These lesions have been seen following trauma in adults. Defects in signalling of TGF-Beta and genetic two-hit hypothesis are the existing theories $[11,12]$.

\subsection{Classifications}

Mulliken and Glowacki [13] in 1982 introduced a biological classification, which classified vascular lesions into two distinct entities: haemangiomas and vascular malformations.

Haemangiomas demonstrate endothelial hyperplasia unlike vascular malformations, which show progressive dilatation of abnormal vessels lined by flat endothelium on a thin basal lamina. A more practical classification amalgamating their biological behaviour and flow dynamics was later introduced [14] (Table 31.1). 
Table 31.1 Modified Mulliken and Glowacki classification [14]

A. Haemangioma
Superficial (Capillary haemangioma)
Deep (Cavernous haemangioma)
Compound (capillary cavernous haemangioma)
B. Vascular Malformations
Simple lesions
Low-flow lesions
Capillary malformations (capillary haemangioma, port-wine
stain)
Venous malformation (cavernous haemangioma)
Lymphatic malformation (lymphangioma, cystic hygroma)
High-flow lesions
Arterial malformation
Combined lesions
Arteriovenous malformations
Lymphovenous malformations
Other combinations

Table 31.2 International Society for the study of Vascular Anomalies classification system (ISSVA) [15]

\begin{tabular}{l} 
Vascular tumors \\
Benign \\
\hline Locally aggressive or borderline \\
Malignant \\
\hline Vascular malformations \\
Slow-flow \\
Capillary malformations \\
Lymphatic malformations \\
Venous malformations \\
Arteriovenous malformations \\
Arteriovenous fistula \\
Combined (2 or more VMs in one lesion) \\
CVM, CLM, LVM, CLVM, CAVM, CLAVM, others \\
(C-capillary, V-venous, L-lymphatic, AV-arteriovenous) \\
Anomalies of major named vessels \\
Vascular malformations associated with other anomalies
\end{tabular}

This system was later revised and adopted by the ISSVA [15] (International Society for the study of Vascular anomalies). This is currently the most widely accepted and divides vascular anomalies into: vascular tumors and vascular malformations (Table 31.2). The online version of the classification, is available on the ISSVA website (www.issva.org), contains hypertext links that facilitate the navigation in the classification and its appendices. These vascular neoplasms show an increased turnover of endothelial cells, which undergo division by mitosis, unlike vascular malformations. Vascular malformations can be capillary, venous, lymphatic and arterial, which progress in proportion to the child.

We proposed a practical classification of vascular lesions based on anatomy and depth of location in the head and neck region [1] (Table 31.3), which helped not only in understanding the extent of lesion but also in determining the surgical approach and reconstruction necessary. This classification is found to be most useful for the surgical management of these complex lesions.
Table 31.3 Anatomical classification of Vascular malformations [1] (IJOMS 2011: 40)

\begin{tabular}{|l|l|}
\hline Type-I & Mucosal/cutaneous \\
\hline Type-II & Sub-mucosal/sub-cutaneous \\
\hline Type-III & Glandular \\
\hline Type-IV & Intra-osseous \\
\hline Type-V & Deep visceral \\
\hline
\end{tabular}

Type-I lesions (Fig. 31.7) are superficial involving the epidermis and dermis. These can be excised in toto and reconstructed with local flaps where necessary. Lasers have some use in such surface lesions.

Type-II lesions (Fig. 31.8) involve sub-cutaneous tissue and facial planes. These can be widespread sometimes and approached by meticulously raising a superficial skin flap. The lesion is either debulked, excised or corseted as necessary (discussed in surgical management).

Type-III lesions (Fig. 31.9) are deeper involving salivary glands, usually parotid and sub-mandibular, demand-raising flaps in sub-cutaneous and sub-dermal planes. The lesion is either debulked, excised or corseted as necessary (discussed in surgical management).

Type-IV lesions (Fig. 31.10) involve bone and are either curetted or excised followed by reconstruction. These are usually high-flow lesions and require ECA control or endovascular embolisation to achieve adequate haemostasis (intra-operative dye administration in Fig. 31.10 demonstrates the efficacy of intra-operative ECA control in treating such high-flow vascular lesions).

Type-V lesions (Fig. 31.11) involve deeper visceral spaces like parapharyngeal, retropharyngeal, glottis and laryngeal. These can be rarely excised intoto and require access osteotomies of maxilla, mandible or zygoma (see Chap. 85 on access osteotomies).

\subsection{Clinical Findings (Table 31.4)}

A comprehensive and holistic understanding of the true nature of lesion is important to adequately manage these patients. The different types will be discussed according to the ISSVA classification for simplicity here, while the surgical management will be discussed according to the anatomical classification, as it was found to be more helpful than other available classifications.

Superficial haemangiomas (Fig. 31.20) can appear as raspberry-coloured birthmarks or reddish discolouration of the skin. The bright red strawberry-like classic appearance may not be seen in deeper lesions involving sub-cutaneous tissues. These deep lesions are wrongly diagnosed as vascular malformation, with normal appearing overlying skin. Superficial lesions were previously called 'capillary hemangiomas', and deeper lesions 'cavernous hemangiomas'. These terms do not reflect the clinical nature or influence the 


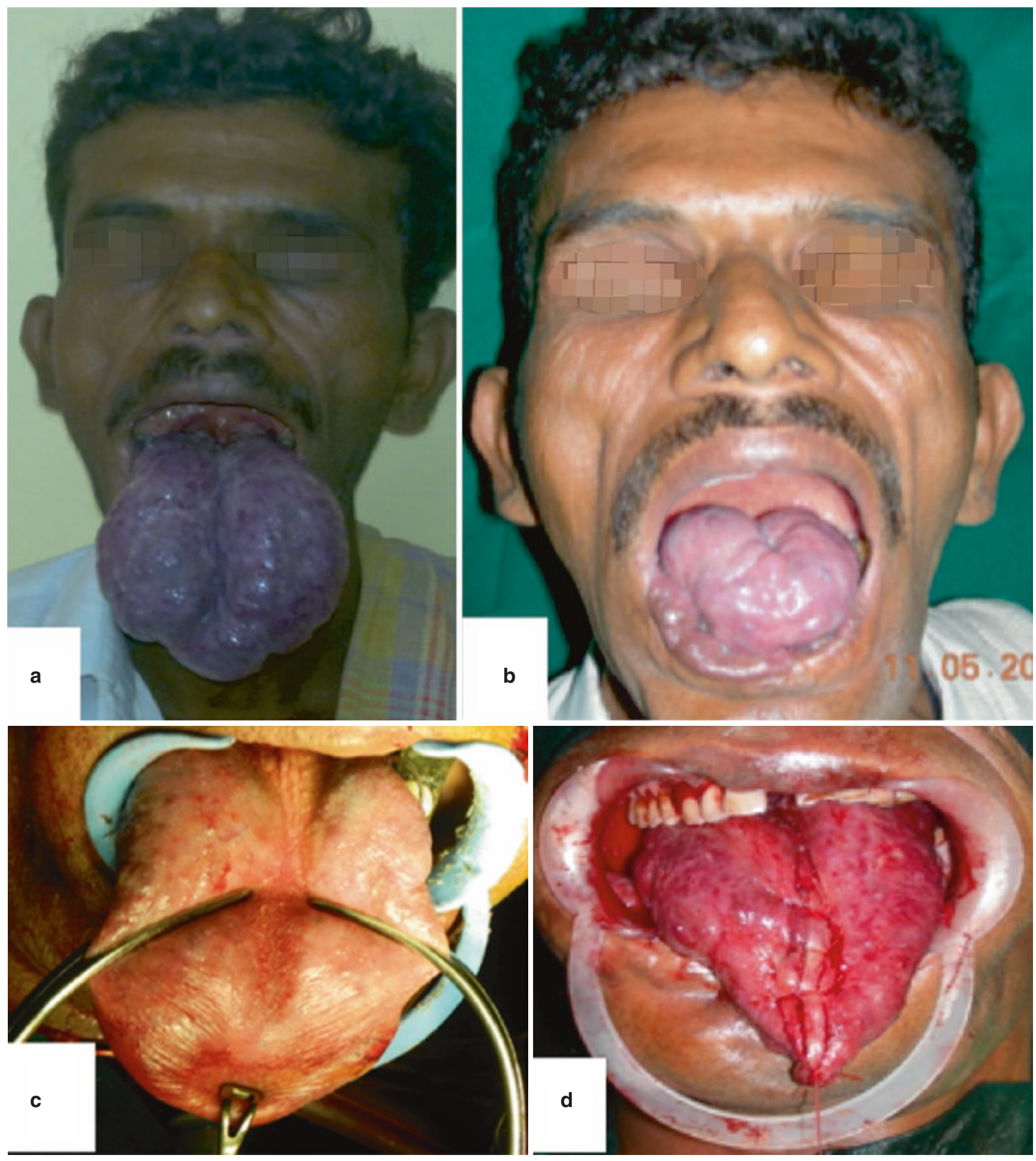

CAssociation of Oral and Maxillofacial Surgeons of India

Fig. 31.7 Type-I vascular lesion ((a) pre-operative tongue VM, (b) debulking, (c) closure and (d) post-operative). Copyright: Authors own publications from IJOMS 2011 

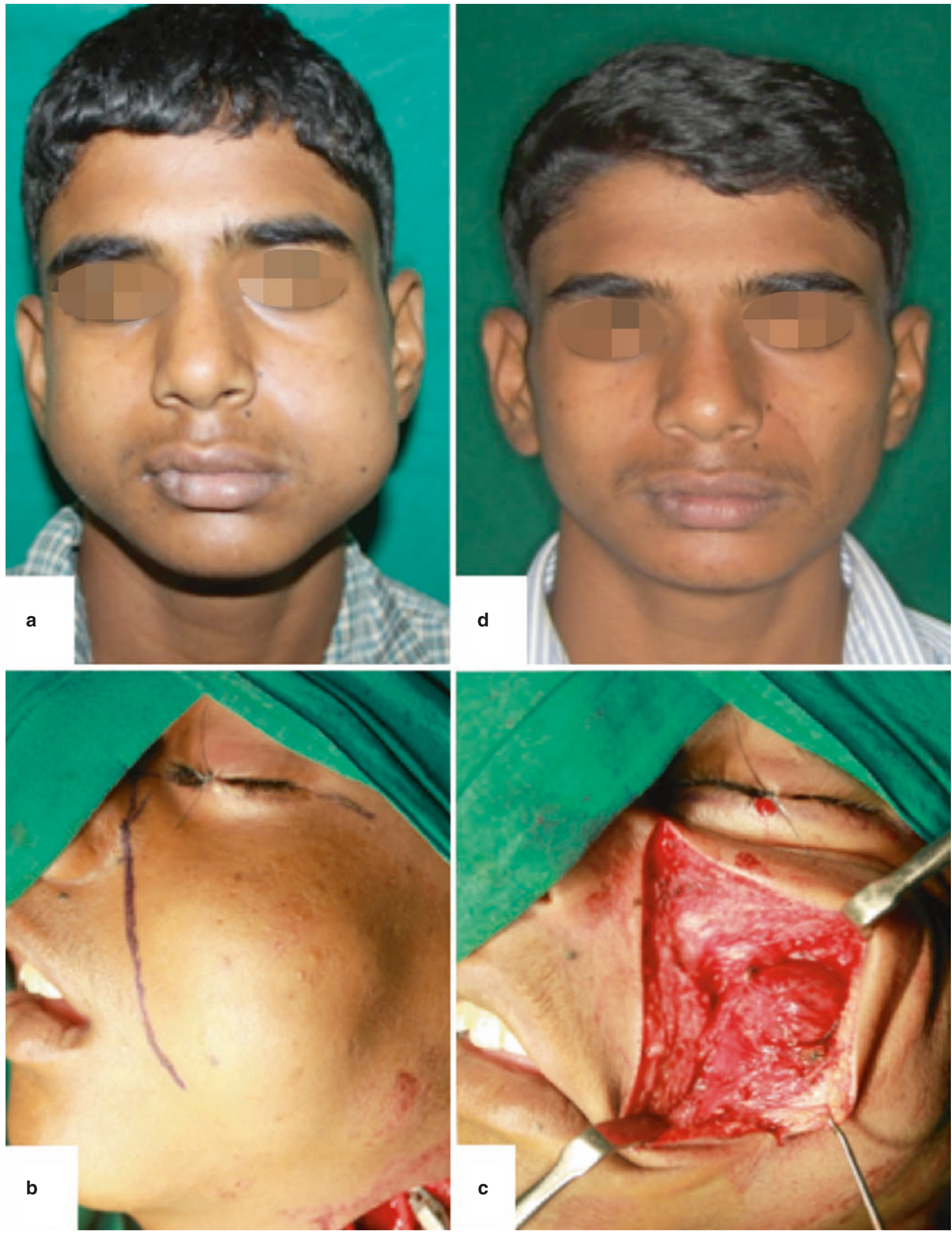

(CAssociation of Oral and Maxillofacial Surgeons of India

Fig. 31.8 Type-II vascular lesion ((a) pre-operative Left cheek VM, (b) incision, (c) exposure and excision and (d) Post-operative) 


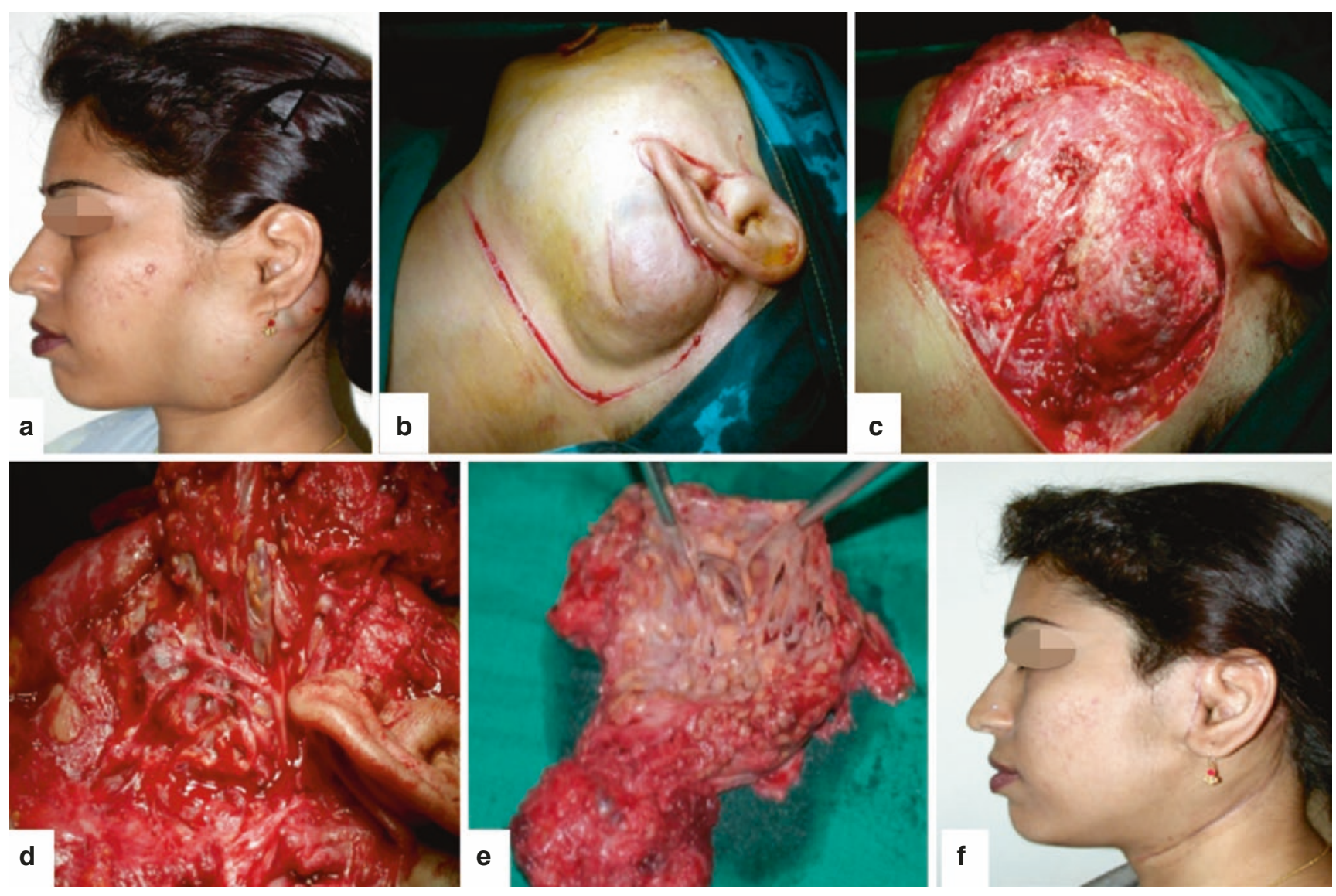

(C)Association of Oral and Maxillofacial Surgeons of India

Fig. 31.9 Type-III vascular lesion ((a) pre-operative Left parotid AVM, (b) incision, (c) exposure, (d) facial nerve dissection, (e) excision specimen and (f) post-operative). Copyright: Authors own publications from IJOMS 2011

treatment and should be reserved only for histological description. Compound lesions involving superficial and deeper tissues are also seen. The clinical appearance may vary depending on the depth of tumour. Growing haemangiomas can show organ involvement and cause ulcerations, bleeding, hearing problems, vision changes, difficulty in mastication, dysphagia and dyspnea.

Congenital haemangiomas are further divided into infantile haemangiomas (IHs), rapidly involuting congenital haemangiomas (RICHs), non-involuting congenital haemangiomas (NICHs) and partially involuting congenital haemangiomas (PICHs) [15, 16].

IHs are commonly seen in infants and occur in $5-10 \%$ of children [17]. They appear anywhere between a few days to 3 weeks after birth. $80 \%$ of these cutaneous lesions are single and $20 \%$ are multiple. They grow rapidly and then enter an inactive phase at about 6 months of age. They then begin to shrink and involute after 1 year of age and sometimes leave behind a residual lesion. These residual lesions take longer to resolve.

RICHs (Fig. 31.20) are present at birth and involute by 6-14 months of age. Occasionally, they cause haematological irregularities like the Kasabach-Merritt phenomenon (KMP).

NICHs (Fig. 31.1) are present at birth and get larger with age. It is best to wait until 1 year of age to differentiate between RICH and NICH by looking at the involution pattern. PICHs initially present as RICH but fail to involute completely and remain as NICH. 


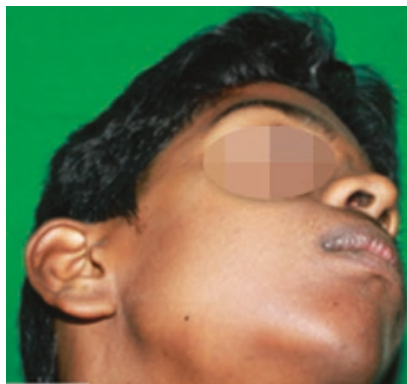

a
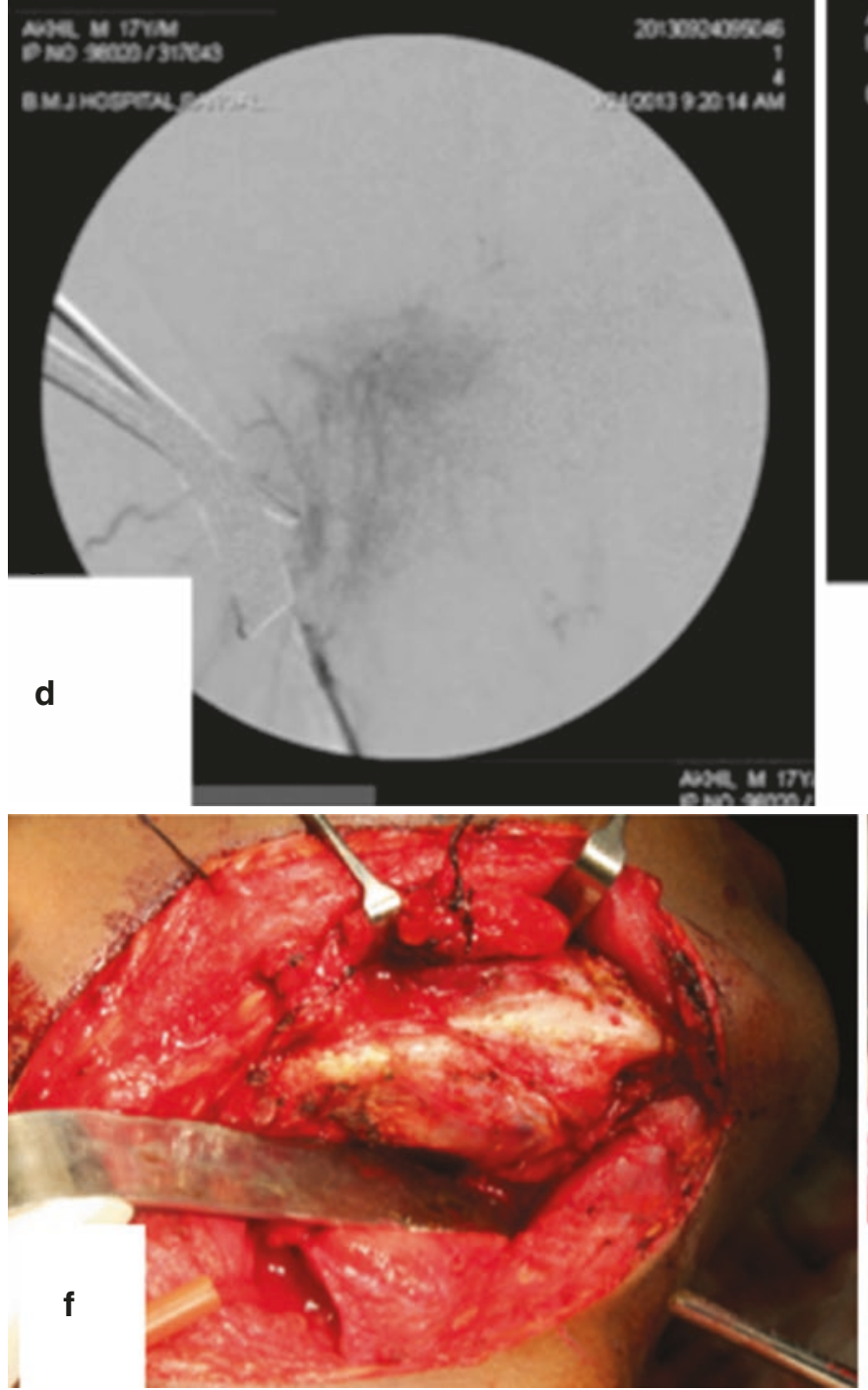

CAssociation of Oral and Maxillofacial Surgeons of India

Fig. 31.10 Type-IV vascular lesion ((a) pre-operative AVM right mandible, (b) axial post-contrast CT image, (c) ECA control and injection of radiopaque dye, (d) intra-operative $\mathrm{C}$-arm picture following dye
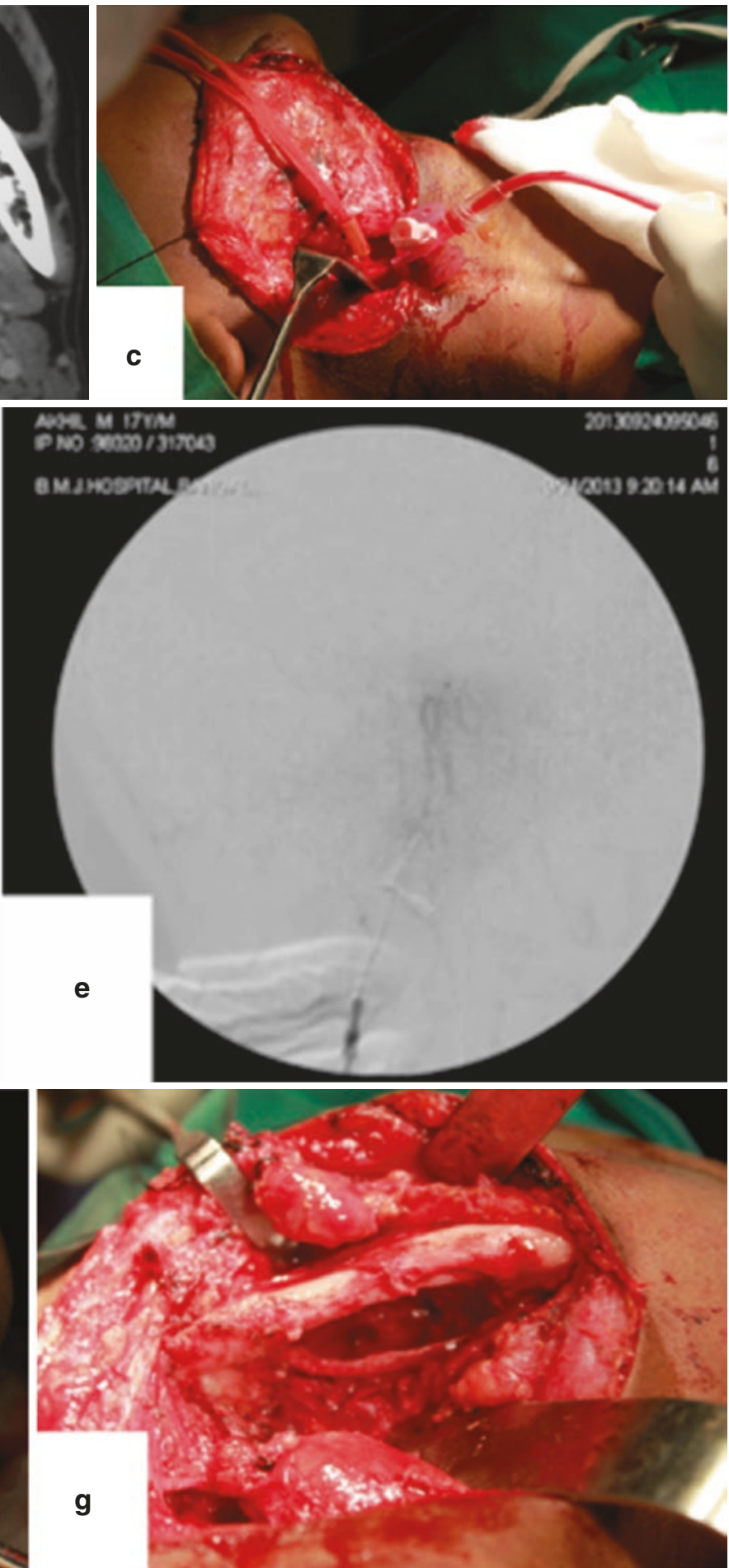

injection before occluding of ECA, (e) intra-operative C-arm picture following dye injection and occlusion of ECA, (f) lesion exposure and (g) currettage of lesion) 

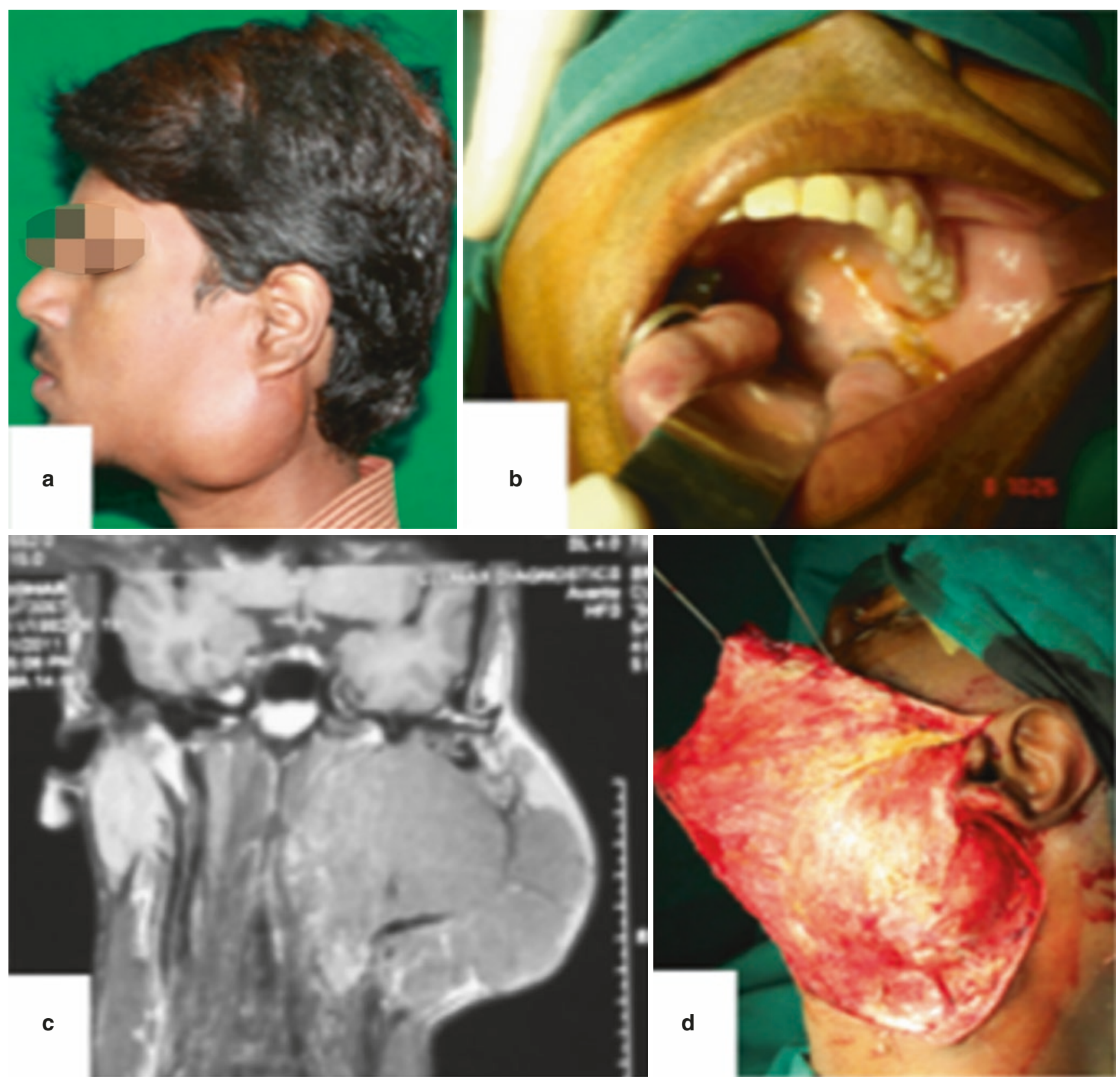

Fig. 31.11 Type-V vascular lesion ((a) pre-operative VM left parotid, (b) parapharyngeal extension, (c) coronal T1 weighted MRI image, (d)

(f) lesion complete currettage, (g) mandibulotomy closure and (h) postexposure, (e) lesion exposure with mandibulotomy and ECA control, 

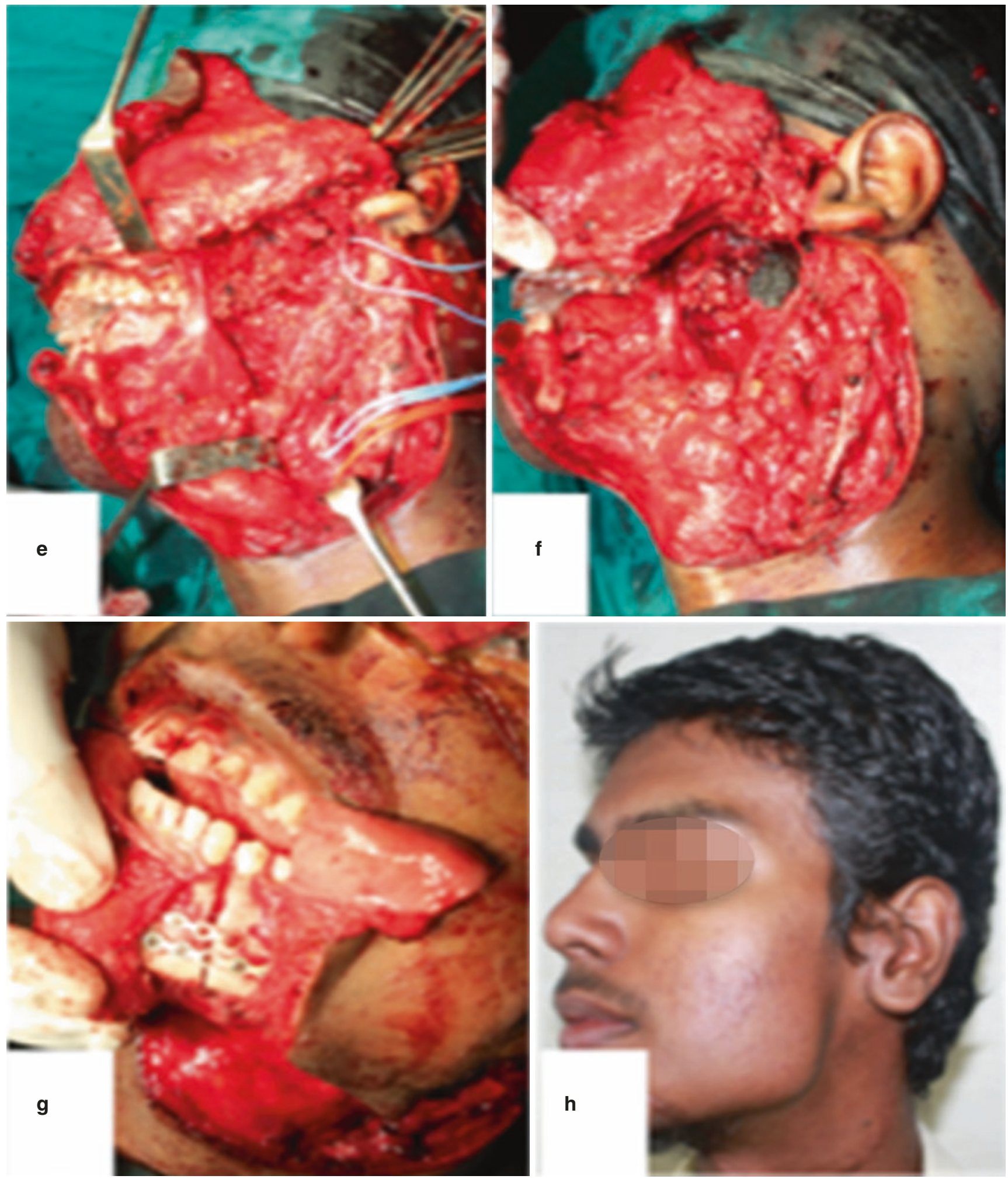

CAssociation of Oral and Maxillofacial Surgeons of India

Fig. 31.11 (continued) 
Table 31.4 Clinical findings of Vascular anomalies of Head and Neck

\begin{tabular}{|c|c|c|c|c|c|c|}
\hline & Haemangioma & VM's & CM's & LM's & AVM's & KHE's \\
\hline Age & $\begin{array}{l}\text { Birth, few days to } \\
3 \text { weeks after birth }\end{array}$ & Birth & Birth & Birth, later in life & Later in life & Neonate \\
\hline Appearance & $\begin{array}{l}\text { Reddish discolouration } \\
\text { of skin }\end{array}$ & Bluish & Red or purple patch & Diffuse swelling & Pink to bluish & - \\
\hline Depth & $\begin{array}{l}\text { Skin, subcutaneous } \\
\text { tissues }\end{array}$ & Superficial, deep & Cutaneous only & Deep tissues & Superficial, deep & - \\
\hline Types & IH, RICH, NICH & - & Medial, lateral & $\begin{array}{l}\text { Macrocystic, } \\
\text { microcystic }\end{array}$ & - & - \\
\hline Behaviour & $\begin{array}{l}\text { Slow growing, } \\
\text { involute in } 12-14 \\
\text { months }\end{array}$ & $\begin{array}{l}\text { Slow growing, } \\
\text { low flow, local } \\
\text { blood stasis }\end{array}$ & $\begin{array}{l}\text { Painless, can involve } \\
\text { deeper structures }\end{array}$ & $\begin{array}{l}\text { Expansile, } \\
\text { infiltrative }\end{array}$ & Pulsatory, thrill & $\begin{array}{l}\text { Large, more } \\
\text { than } 5 \mathrm{~cm} \text { in } \\
\text { size }\end{array}$ \\
\hline $\begin{array}{l}\text { Functional } \\
\text { problems }\end{array}$ & $\begin{array}{l}\text { Ulceration, vision/ } \\
\text { hearing/swallowing/ } \\
\text { airway issues }\end{array}$ & $\begin{array}{l}\text { Painful } \\
\text { thrombophlebitis, } \\
\text { phlebolith } \\
\text { formation }\end{array}$ & $\begin{array}{l}\text { Cosmetic } \\
\text { disfigurement, involve } \\
\text { other areas like in } \\
\text { Sturge Weber } \\
\text { syndrome, Klippel } \\
\text { Trenaunay syndrome }\end{array}$ & $\begin{array}{l}\text { Airway problems, } \\
\text { pain, dysphagia, } \\
\text { difficulty in } \\
\text { mastication }\end{array}$ & $\begin{array}{l}\text { Coagulopathy LIC/ } \\
\text { DIC, throbbing } \\
\text { pain, ulceration }\end{array}$ & $\begin{array}{l}\text { Thrombocyte } \\
\text { penia, } \\
\text { Kasabach- } \\
\text { Merritt } \\
\text { phenomenon }\end{array}$ \\
\hline
\end{tabular}

Venous malformations (VMs) (Fig. 31.3) are most commonly seen vascular malformations, which are slowgrowing, low-flow lesions present at birth and demonstrate a network of serpiginous inter-woven veins. These can grow extensively, become palpable, discoloured or bluish in colour with local blood stasis, which sometimes lead to painful thrombophlebitis. VMs can increase in size, in proportion to the increase in pressure within vessels caused by valsalva manoeuvre, dependency, exercise or agitation. VMs are usually compressible on palpation. They can demonstrate 'pheboliths', which are nothing but small calcifications formed due to, prolonged intra-vascular coagulation (Fig. 31.12).

Phleboliths are the commonest cause of pain in VMs. There is progressive lamellar fibrosis following intravascular thrombus formation. Calcium phosphate and carbonate are deposited in the core of the thrombus with peripheral mineralisation [18], which slowly increases in size. They are clinically palpable intra-orally, bi-manually in the cheek and over bony prominences. These are present as multiple oval or round laminated bodies (Fig. 31.12) with radiolucent or radiopaque corners, radiologically. Phleboliths can be areas of resistance to injecting sclerosants and should be excised separately.

Capillary malformations (CMs) (Fig. 31.4), can be seen in the neonatal period and should not be mistaken with infantile haemangiomas (IHs). They occur in around $0.3 \%$ of children presenting with vascular anomalies. CMs usually present congenitally as a flat, red or purple cutaneous patch with asymmetric borders. They are painless and do not bleed spontaneously. They are categorised as 'medial' or 'lateral' lesions, based on their location in head and neck. Lateral lesions involve areas of face along the distribution of trigeminal nerve. They present as portwine stains, usually increase in size to involve deeper sub-cutaneous tissues causing the lesions to become darker, more raised and nodular. CMs may be part of a syndrome, commonly the Sturge-Weber syndrome, which is characterised by CM involving the ophthalmic branch of trigeminal nerve, leptomeningeal angiomatosis and choroid angioma. CMs may also be seen in the KlippelTrenaunay syndrome with multiple vascular (lymphatic, venous and capillary) abnormalities.

Lymphatic malformations (LMs) (Fig. 31.5) are usually congenital and not always detected until later in life. LMs are slow-flow lesions and can be macro-cystic $(>2 \mathrm{~cm})$ (Fig. 31.5b), micro-cystic $(<2 \mathrm{~cm})$ (Fig. $31.5 \mathrm{a})$ or mixed, depending on the size of predominant cysts within them. Macro-cystic LMs can show expansion and compression of adjacent anatomical structures in the head and neck causing dysphagia, dyspnea and masticatory problems. Micro-cystic LMs were previously called lymphangiomas and demonstrate an infiltrative nature. LMs with local haemorrhage and infection can cause significant pain. LMs of the head and neck are further described by the de Serres classification scheme [19], which classifies disease severity based on the location and prognosis.

Fast-flow arterio-venous malformations (AVMs) (Fig. 31.6), usually present with a pulsatile local swelling. These AVMs along with some slow-flow lesions are at an increased risk of haematological complications like coagulopathies due to disturbances in haemostasis and thrombosis. Blood pools in abnormal slow-flow vessels, resulting in activation of the coagulation system, resulting in a process known as 'localized intravascular coagulopathy' (LIC), which shows low fibrinogen, elevated D-dimer levels and mild thrombocytopaenia. This can further cause, 'disseminated intravascular coagulopathy' (DIC) and consumption of various coagulation factors.

AVMs are known to behave aggressively in later life, which can be stimulated by pubertal changes, pregnancy or trauma. They may present with throbbing pain, ulceration 

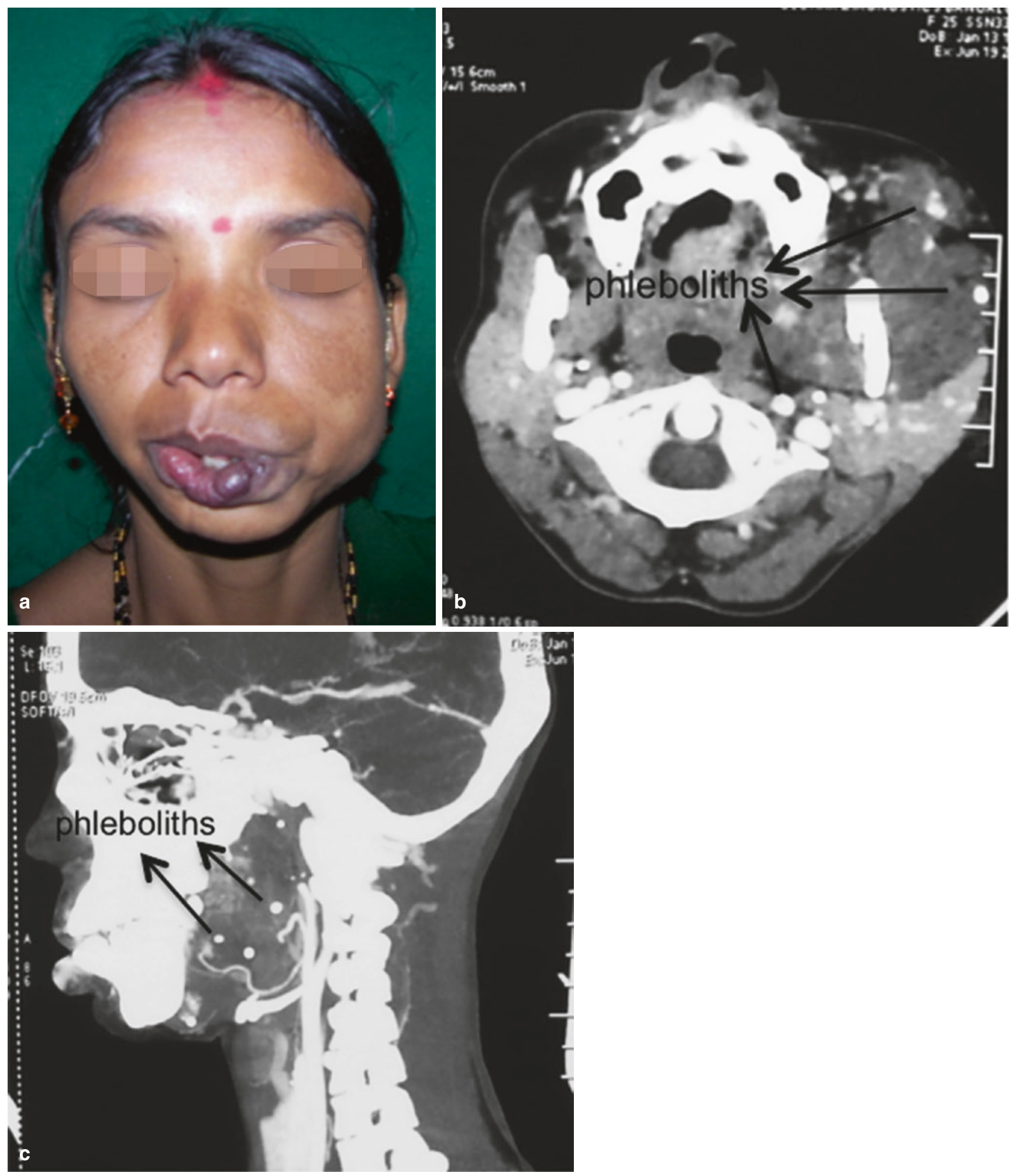

CAssociation of Oral and Maxillofacial Surgeons of India

Fig. 31.12 Left cheek and lower lip VM ((a) clinical picture, (b, c) post-contrast axial and sagittal CT images showing multiple phleboliths) 
and bleeding. Significant bleeding can sometimes be a cause of cardiac failure, in affected individuals.

A useful clinical staging system was introduced by Schobinger [20] in 1990. This system is widely used for describing the clinical presentation and evolution of AVMs:

Stage I (quiescence): pink-bluish stain, warmth and arteriovenous shunting by way of Doppler examination

Stage II (expansion): same as stage I, plus enlargement, pulsations, thrill, bruit and tense/tortuous veins

Stage III: the same as stage II, plus dystrophic skin changes, ulceration, (destruction) tissue necrosis, bleeding or persistent pain

Stage IV: the same as stage III, plus cardiac failure (decompensation)

Undiagnosed AVMs of bone are occasionally the cause of increased bleeding during/after extraction of teeth in a dental office, which can lead to life-threatening airway and haematological problems if not treated immediately (Fig. 31.13). These warrant urgent transfer to a hospital and embolisation or ECA control.

Hereditary haemorrhagic telangiectasia (HHT) is autosomally dominant and presents with the formation of expanding arterio-venous fistulas. These patients usually present with superficial (skin, mucosal) or deep (visceral) telangiectatic lesions. They may sometimes present with aneurysms causing epistaxis or intra-cranial haemorrhage.

Kaposiform haemangioendotheliomas (KHEs) are large lesions (greater than $5 \mathrm{~cm}$ ), which are present in the neonatal period. They are extremely rare and have a low incidence of occurrence. Hence, there are no clear guidelines on their management. These are aggressive vascular tumours, which can be complex in their management due to thrombocytopaenia secondary to platelet trapping. This phenomenon is known as KMP (Kasabach-Merritt phenomenon). $70 \%$ of patients with KHEs demonstrate this phenomenon [21].

\subsection{Radiological Assessment}

Clinical and radiological assessment go hand in hand to accurately diagnose and manage these diverse groups of head and neck vascular anomalies. Selection of the imaging should be tailored according to the indication, advantages, disadvantages and availability of resources. Good knowledge of all the available radiological modalities is essential to treat these lesions.

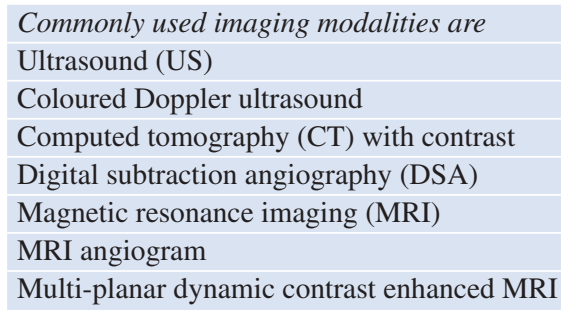

US (Fig. 31.14) is the least invasive modality of imaging available for assessment of vascular anomalies. It is used as a baseline investigation for superficial head and neck vascular lesions. In addition to the above, the US has a high sensitivity in diagnosing these lesions. The disadvantages of the US are its limitation in detecting deeper soft tissue and bony lesions.

Doppler ultrasound (Fig. 31.15) is used to demonstrate high-flow lesions. Flow towards the ultrasound transducer is seen in red and away from the transducer seen in blue. The arterial feeder is usually identified by increased colour flow, high doppler shift and low resistance.

CT (Fig. 31.16) is used to diagnose bony lesions, provide cross-sectional details and detect the presence of calcifications like phleboliths in venous malformations and haemangiomas. Most scans can be done in less than a minute with quick acquisition time. Reduced imaging time and low cost compared to MRI make contrast CT widely used for diagnosing soft tissue vascular lesions. Surveillance imaging with CT is not recommended due to increased exposure to ionising radiation.

MRI (Fig. 31.17) is the most preferred and accepted imaging for diagnosing and monitoring soft-tissue vascular lesions of head and neck. Its superior contrast resolution, indepth soft-tissue assessment and non-exposure to ionising radiation, makes it the investigation of choice for these lesions. Haemangiomas and VMs show intense enhancement with MRI. AVMs and LMs show minimal enhancement.

Fat-suppressed T2-weighted imaging is used to discriminate these lesions among each other. Intense T2-weighted signal is seen with VM's and macro-cystic LM's due to cystic spaces within them and pooling of slow-flowing blood or lymph. Moderate signal intensity is seen with haemangiomas and vascular neoplasms due to their cellular composition. Mild T2-weighted signal is seen with AVM's reflecting tissue oedema.

Long acquisition time (at least $30 \mathrm{~min}$ ) and increased cost of imaging limit its use [22]. Use of sedation or anaesthesia is required for infants, children and uncooperative adults.

Angiography (Fig. 31.18) is usually reserved for therapeutic endovascular interventions. Angiography includes arteriography, venography and injection of direct intralesional contrast agent. This provides good resolution (spatial and temporal) of the vascularity and also permits catheter-induced percutaneous therapy. Arteriography is used for the evaluation of high-flow vascular lesions. Its use is limited due to the invasive nature and use of ionising radiation.

DSA (Fig. 31.19) should be reserved for patients undergoing endovascular treatment. DSA is used for diagnosis of AVM's where the feeding artery, draining vein, nidus connecting artery and vein can be clearly imaged [23] and simultaneous embolisation can be performed, by an interventional radiologist. 

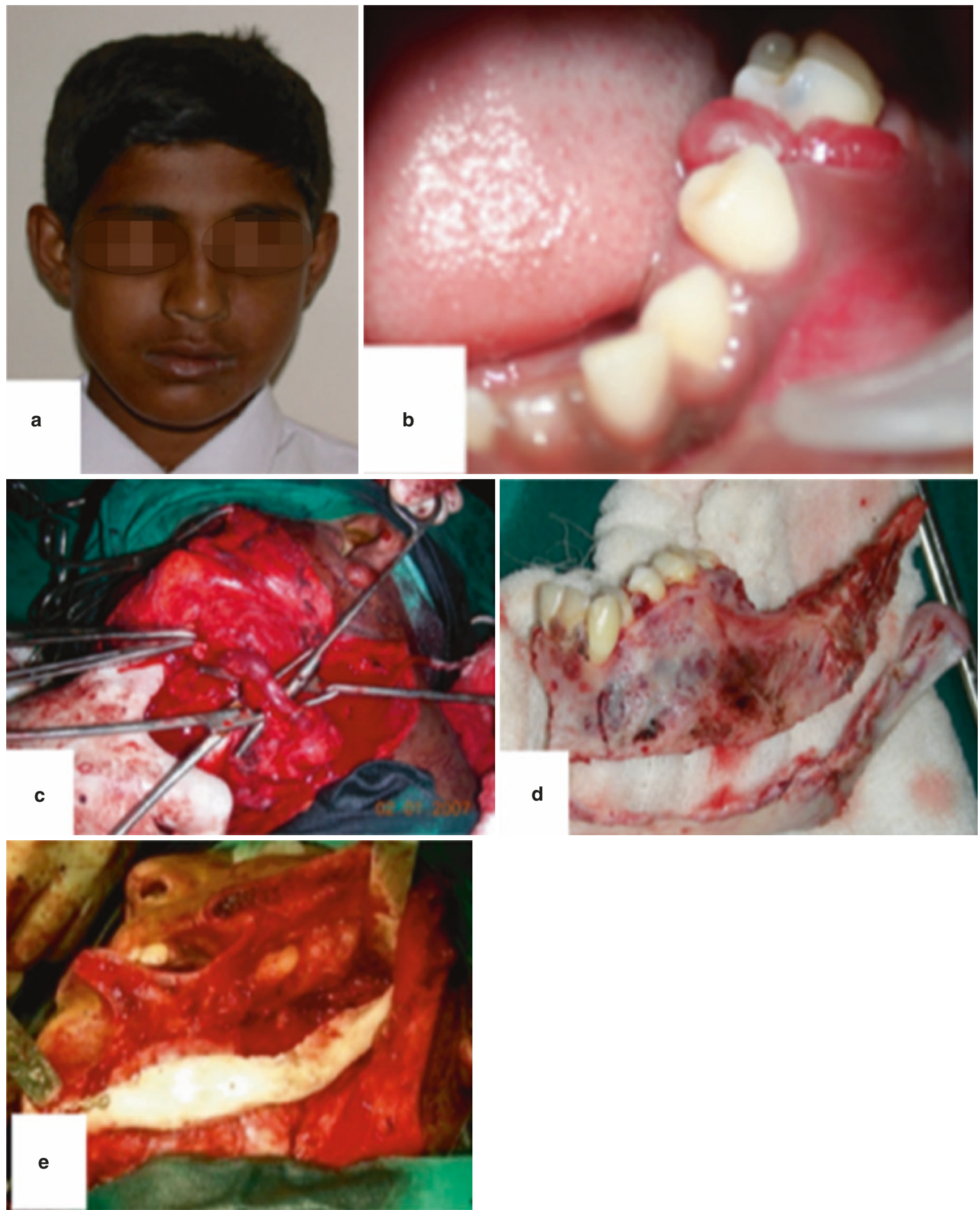

(CAssociation of Oral and Maxillofacial Surgeons of India

Fig. 31.13 Bleeding following dental extraction-Extracorporeal currettage of high-flow bony vascular lesion and fixation of mandible ((a) pre-operative, (b) intra-oral, (c) ligation of main feeder, (d) extra-cor- poreal currettage and excision of diseased bone and (e) fixation of mandible as the free graft) 


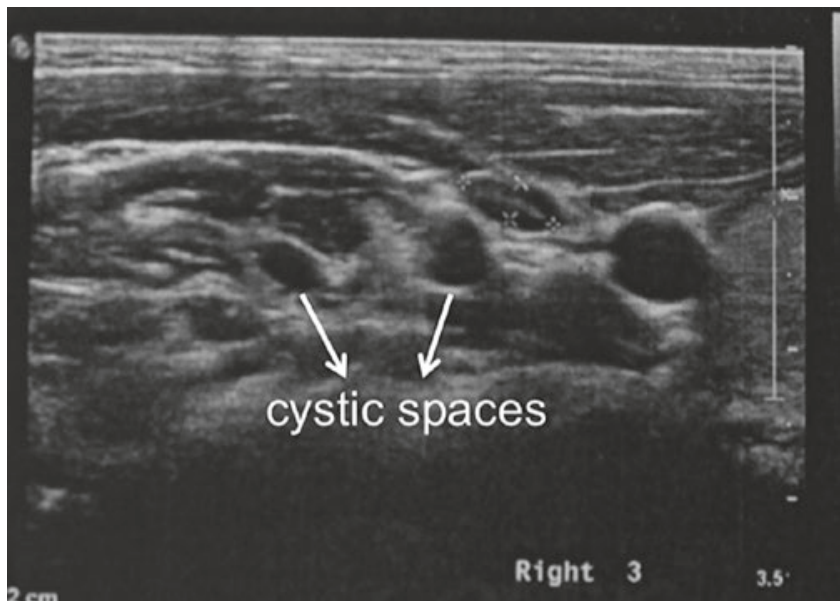

CAssociation of Oral and Maxillofacial Surgeons of India

Fig. 31.14 Ultrasound image-Venous malformation of submandibular region showing multiple cystic spaces

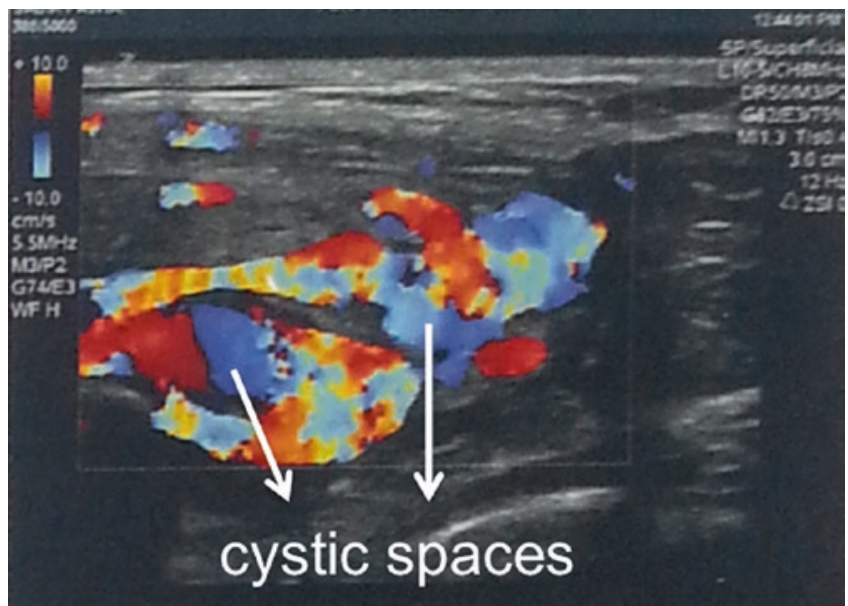

CAssociation of Oral and Maxillofacial Surgeons of India

Fig. 31.15 Coloured Doppler Ultrasound image of AVM of neck showing multiple cystic spaces filled with colour (flow towards the transducer seen in 'red' and away in 'blue', lighter shades of colour depict higher velocity)

Multi-planar dynamic contrast-enhanced MRI is preferred for extensive vascular malformations of the head and neck, especially in lesions involving aerodigestive tract, neural and vascular structures.

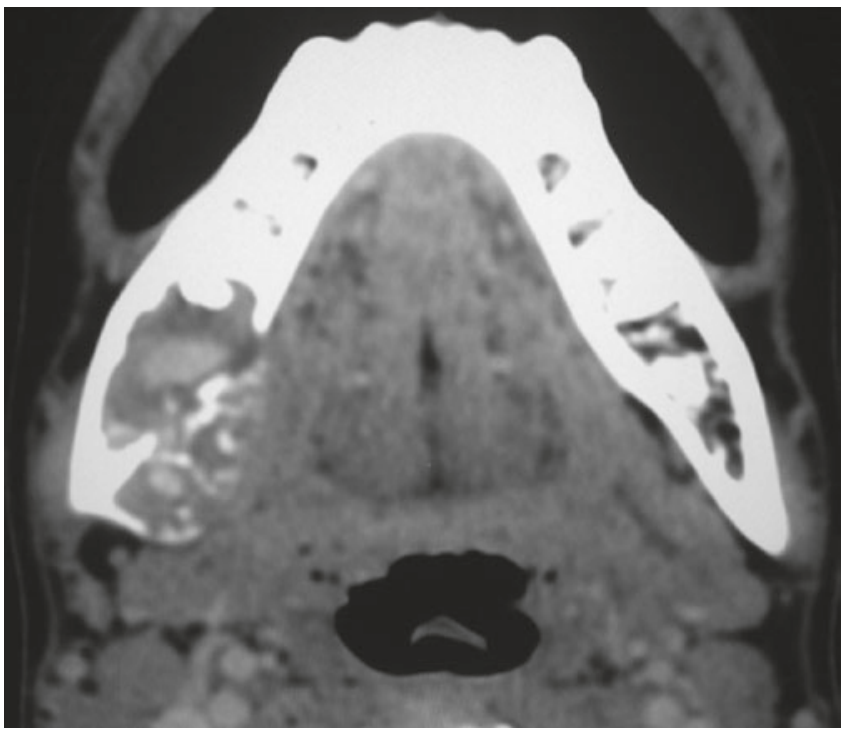

CAssociation of Oral and Maxillofacial Surgeons of India

Fig. 31.16 CT with contrast, Right mandible Type-IV lesion

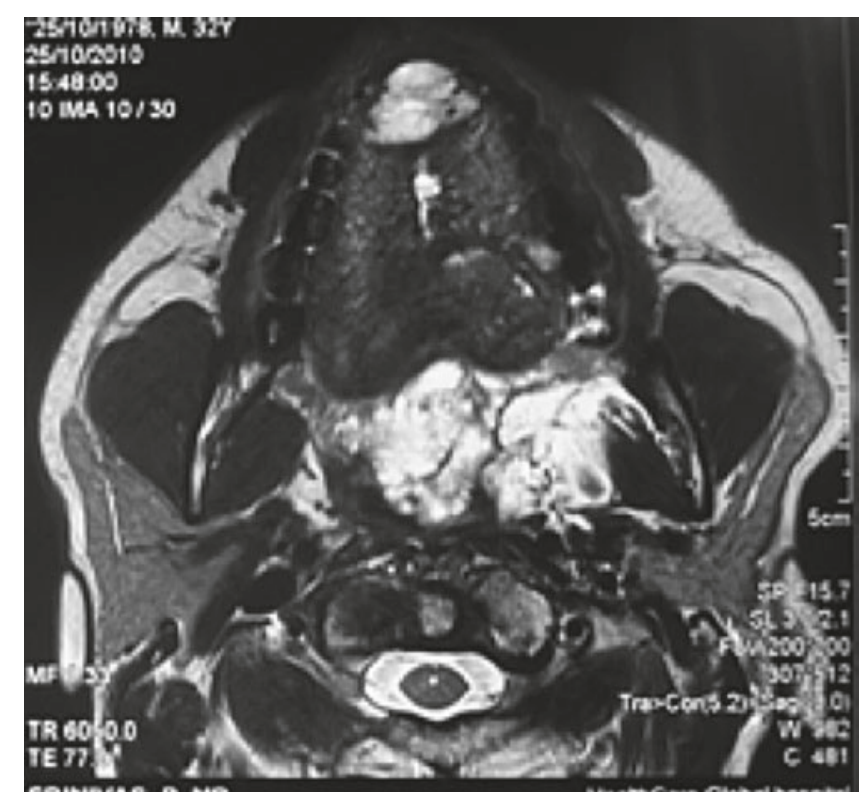

CAssociation of Oral and Maxillofacial Surgeons of India

Fig. 31.17 T2-weighted MRI, left parapharyngeal venous malformation 

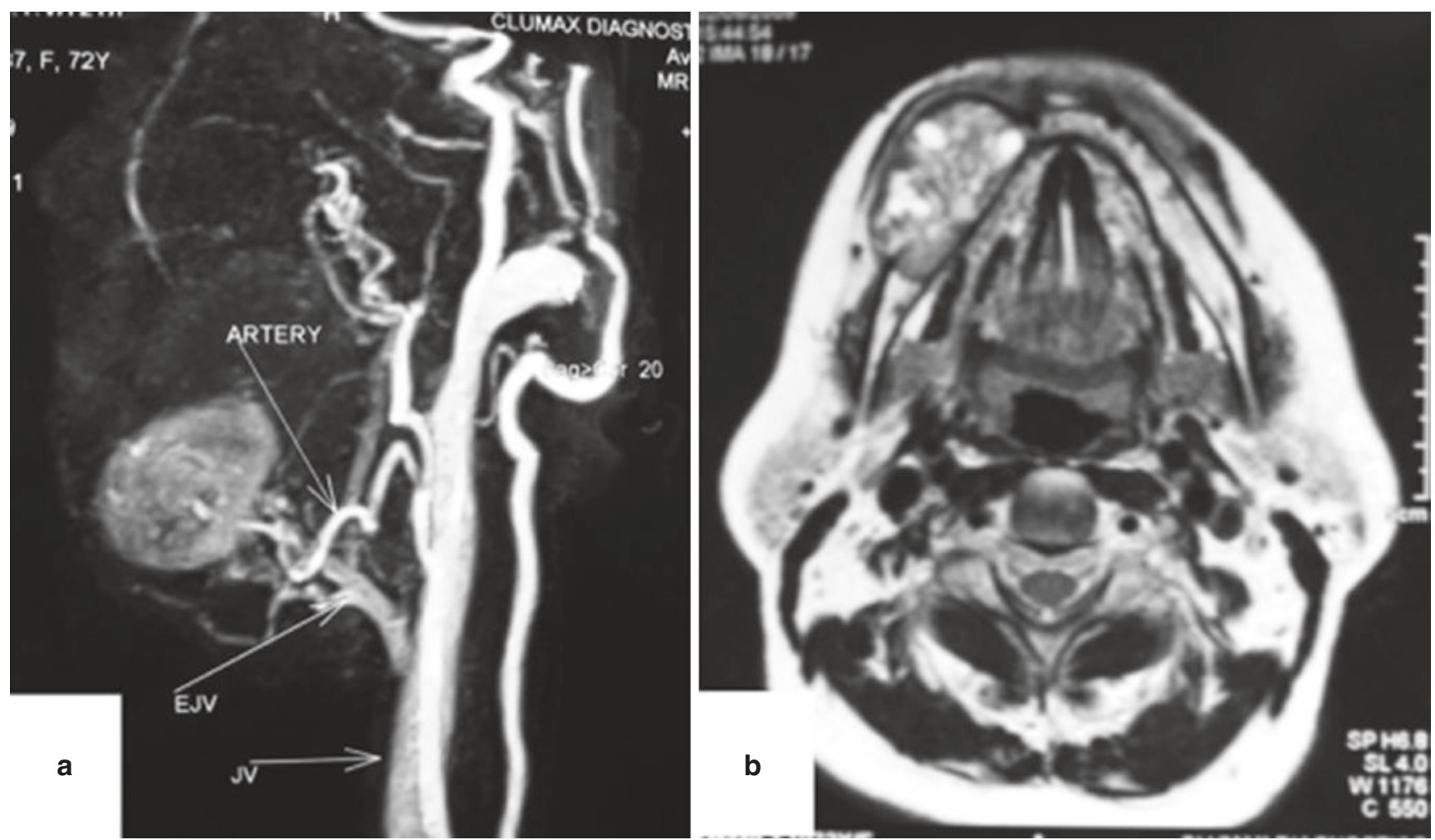

CAssociation of Oral and Maxillofacial Surgeons of India

Fig. 31.18 AVM of right mandible ((a) Contrast MR angiography image, (b) T2-weighted MRI image). Copyright: Authors own publications from IJOMS 2011
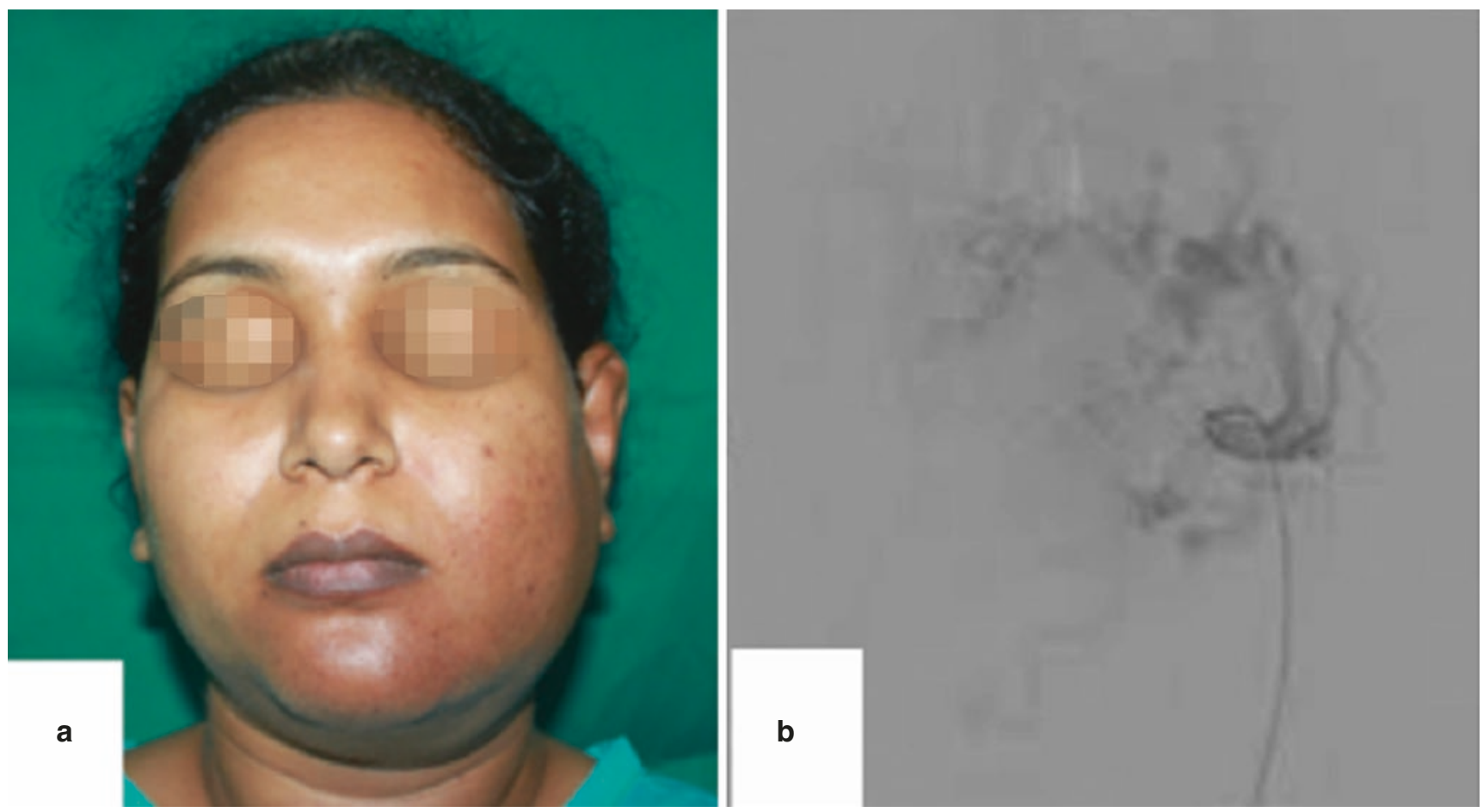

CAssociation of Oral and Maxillofacial Surgeons of India

Fig. 31.19 AVM left cheek ((a) clinical image, (b) DSA image during embolization) 


\subsection{Medical and Interventional Management}

Correct diagnosis is important for selecting the appropriate therapy for vascular anomalies.

The aim of managing complex vascular lesions should be to relieve acute symptoms like pain, swallowing and airway problems, prevent and treat thromboembolic events and correct the cosmetic impairment caused by them.

The type of vascular anomaly and its flow characteristics, determine the mode of management.

These mostly fall into:

- Medical line of management,

- Interventional therapy and

- Surgical management.

Congenital haemangiomas, low flow venous malformations and lymphangiomas can be considered for treatment with systemic and sclerotherapy. Residual and large lesions are usually treated with surgery. AVM's and high-flow malformations have been mostly treated using embolisation with or without surgical excision/debulking successfully.

The author's wide experience in the surgical management of most low- and high-flow lesions has provided acceptable and predictable results.

In haemangiomas, a 'wait and observe' strategy is preferred. Involution is seen in more than $85 \%$ of patients. If a malignant lesion is suspected, a biopsy with a request for GLUT-1 immunostaining is required to confirm its true nature [24]. Active intervention is considered if the lesion is

- Large in size causing obvious facial asymmetry

- Multiple with systemic changes like high-output cardiac failure.

- Adjoining or involving important structures like airway, eye and ear causing_-vision, hearing, airway or swallowing problems.

- Recurrent and persisting ulcerations

Propranolol (Fig. 31.20) is the first line of treatment and is best to involve a paediatrician to monitor the dosage and systemic complications associated with it. Propranolol causes vasoconstriction and possibly reduced expression of pro-angiogenic factors of the haemangioma growth phase, leading to apoptosis of capillary endothelial cells.

Treatment during the proliferating phase is given to prevent impending functional or aesthetic complications especially
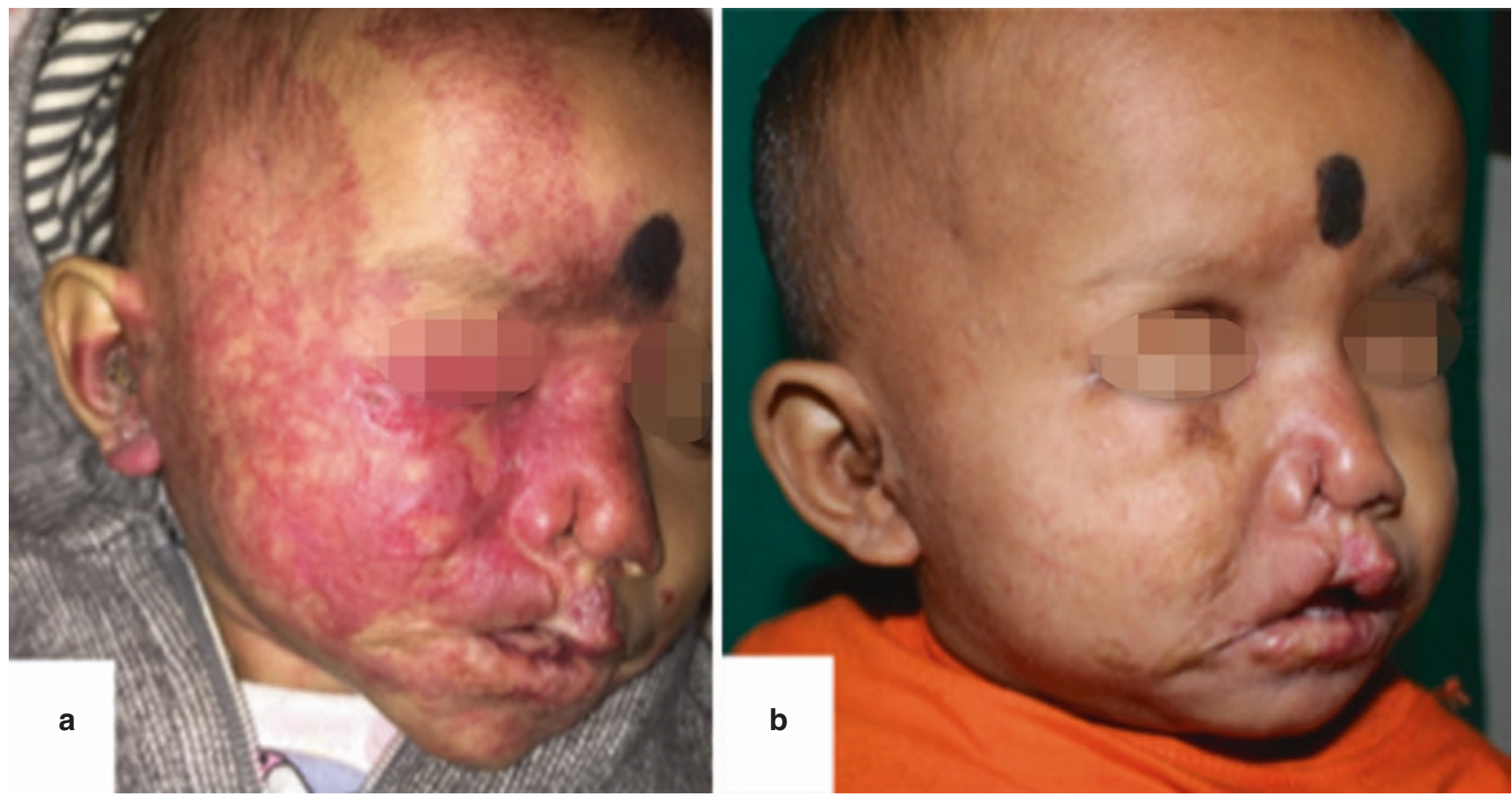

CAssociation of Oral and Maxillofacial Surgeons of India

Fig. 31.20 Rapidly involuting congenital Haemangioma (RICH) of right face treated with propanolol therapy ((a) pre-treatment, (b) post-treatment) 
near vital areas like eyes and ear. In the absence of contra-indications to propranolol like sensitivity to beta-blockers, bronchospasm, hypotension or bradycardia and after having a routine haematological and biochemical assessment by the paediatrician, a dose of $1 \mathrm{mg} / \mathrm{kg} /$ day in three divided doses may be initiated and titrated up to $2 \mathrm{mg} / \mathrm{kg} / \mathrm{day}$. This is given for 12 months or longer according to the response. Meticulous dose adaptation is important to prevent adverse effects. These could be bradycardia, increased airway resistance, bronchial obstruction and hypotension.Long-term effects of propranolol are still not known and other drugs like timolol have been tried for superficial and peri-ocular lesions. Invasive therapies are almost never required to treat these lesions.

Although propranolol has replaced the use of systemic steroids as the first line therapy for haemangiomas, intralesional therapy for localised lesions with, Triamcinolone may be used with a dose of $2 \mathrm{mg} / \mathrm{kg}$ every 4-6 weeks depending on the response. It is known that one-third of patients do not respond to treatment with steroids. Systemic steroids are sometimes given in conjunction with propranolol after consulting with the paediatrician.

Rebound growth being a problem with systemic therapy using propranolol and/or steroids, the dose is always preferred to be tapered-off before discontinuing following resolution of the lesion.

Embolisation is considered in patients with high-output cardiac failure and large-aggressive lesions causing problems with haemostasis.

Surgery is considered between 2 and 4 years of age after having attempted medical treatment to minimise deformity involving eyes, nose and lips and other areas of face.

Pulsed dye laser was used in past for coagulating the surface of ulcerated lesions. This is now used for the treatment of surface residual telangiectasia, usually after 10 years of age (Algorithm 31.1)

Minimally invasive percutaneous sclerotherapy is used widely for the treatment of venous malformations. A wide range of agents are known to be used in the literature. There is no consensus on choice of sclerosant to be used. Commonly used sclerosants [25] are pingyangmycin (PYM), absolute ethanol, OK-432 (picibanil), ethanolamine oleate, bleomycin, polidocanol, doxycycline and STS (Sodium tetradecyl sulphate).

PYM [25], also known as Bleomycin A5, is the most commonly used single-drug therapy for the treatment of cervicofacial malformations. Transient fever and swelling are commonly seen side effects. Skin ulceration and subcutaneous tissue atrophy are scarcely seen complications.

Absolute ethanol [25] causes alteration in cellular proteins and hence damages the endothelium of the vascular wall leading to obliteration of its lumen. Common complications include, nerve injury, necrosis and ulceration of skin.

OK-432 [25] is a lyophilised preparation of low-virulence bacteria, group A Streptococcus pyogenes, incubated with

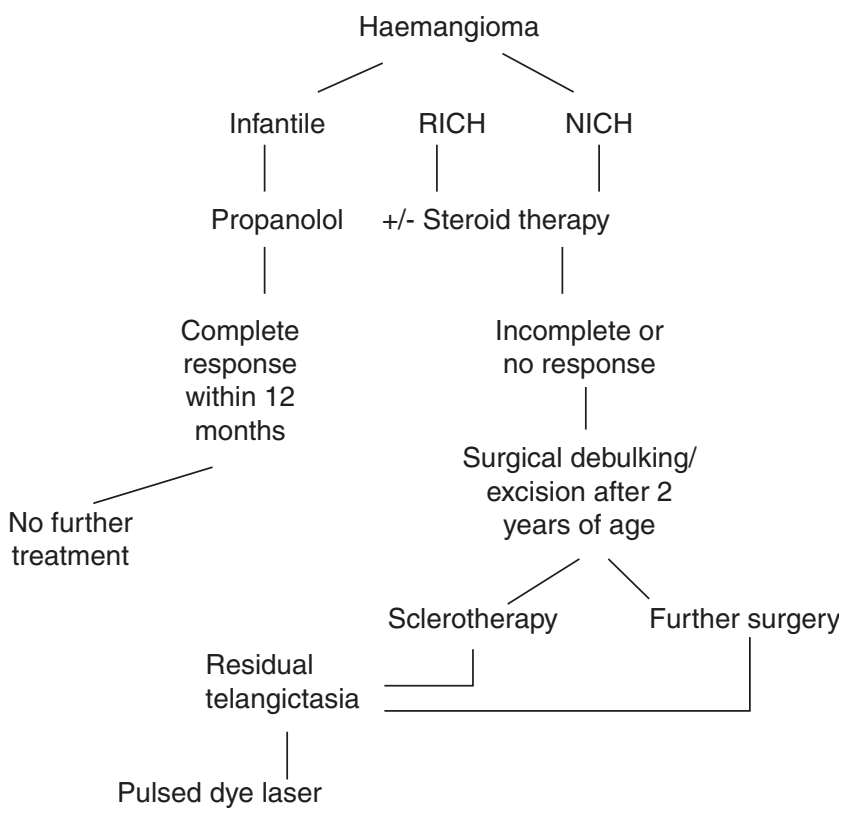

Algorithm 31.1 Management of Haemangioma

benzyl- penicillin. It causes, induction of various cytokines. The inflammatory response caused by this remains localised and causes endothelial damage. The complications include local swelling and transient facial nerve palsy.

Ethanolamine oleate [25] is an emulsion of fatty acids, which induces thrombosis and damages the endothelium. Complications like ulceration and necrosis of skin are known but infrequently observed.

Bleomycin [25] was first used in the treatment of cystic hygromas (now lymphatic malformation). It is now used widely for management of lymphatic and venous malformations. It inhibits DNA synthesis and has a non-specific inflammatory reaction on the endothelial cells. Adverse effects of bleomycin are minimal and transient, mostly being localised pain and swelling. Skin infections in the area of injection are seen less commonly. Some people report with occasionally severe nausea.

Polidocanol [25] is a non-ionic detergent, causes absorption at the cell membrane and leads to lysis of endothelial lining. Superficial necrosis of skin or mucosa is a known complication with Polidocanol.

Doxycycline [25] belongs to the tetracycline group of antibiotics. Its mode of action is not yet clear, but its effects are known to be due to inhibition of matrix metalloproteinases and cell proliferation. It also causes suppression of vascular endothelial growth factor during angiogenesis and lymphangiogenesis. This further leads to dense adhesions and fibrosis due to collagen and fibrin deposition. Macrocystic LM's show a better response to treatment with doxycycline in comparison to micro-cystic LM's. Haemorrhage, cellulitis, pain and transient oedema are com- 
monly seen complications. Scarring, skin excoriation and horner syndrome are seen less commonly. These adverse effects are self-limiting and likely to be related to the sclerosing effect rather than a side effect of the medication itself.

STS [25], also known as sotradecol, causes denaturation of proteins like clotting factors due to disruption of the normal architecture of the lipid bilayer in cell membranes of endothelial cells. This causes fibrosis and occlusion of vessels. It is not known to have any major complications so far.

Lymphatic malformations are treated depending on the type and location in head and neck. As mentioned previously, these lesions can cause pressure on the airway, aerodigestive tract and enlarge due to repeated infection or haemorrhage into the lesion. In the majority of patients with macro-cystic LMs, sclerotherapy with Picibanil ( $O K$ 432) has shown good results. Patients may develop inflammation at the site of injection and fever, which is managed symptomatically. Micro-cystic LMs may require systemic therapy with Sirolimus or surgery as they do not always respond to Picibanil. Sirolimus is a natural macrolide secluded from Streptomyces genus (Streptomyces hygroscopicus). It causes a decrease in the vascular endothelial growth factor (VEGF) and is a key regulator in lymphangiogenesis and angiogenesis.

Bleomycin is used widely for the treatment of VMs and microcystic LMs. The mechanism of action on micro-cystic disease is not completely understood and may involve derangement of tight junctions between endothelial cells or induction of endothelial mesenchymal transition. The overall response is favourable but complete response is seen in only about $20-57 \%$ [25]. The author follows a protocol of intralesional injection of $15 \mathrm{IU}$ Bleomycin in $5 \mathrm{ml}$ of fresh normal saline, administered every 15 days. Most patients show a response in 3-4 sittings (Fig. 31.21). Lymphatic malformations are known to cause sec-
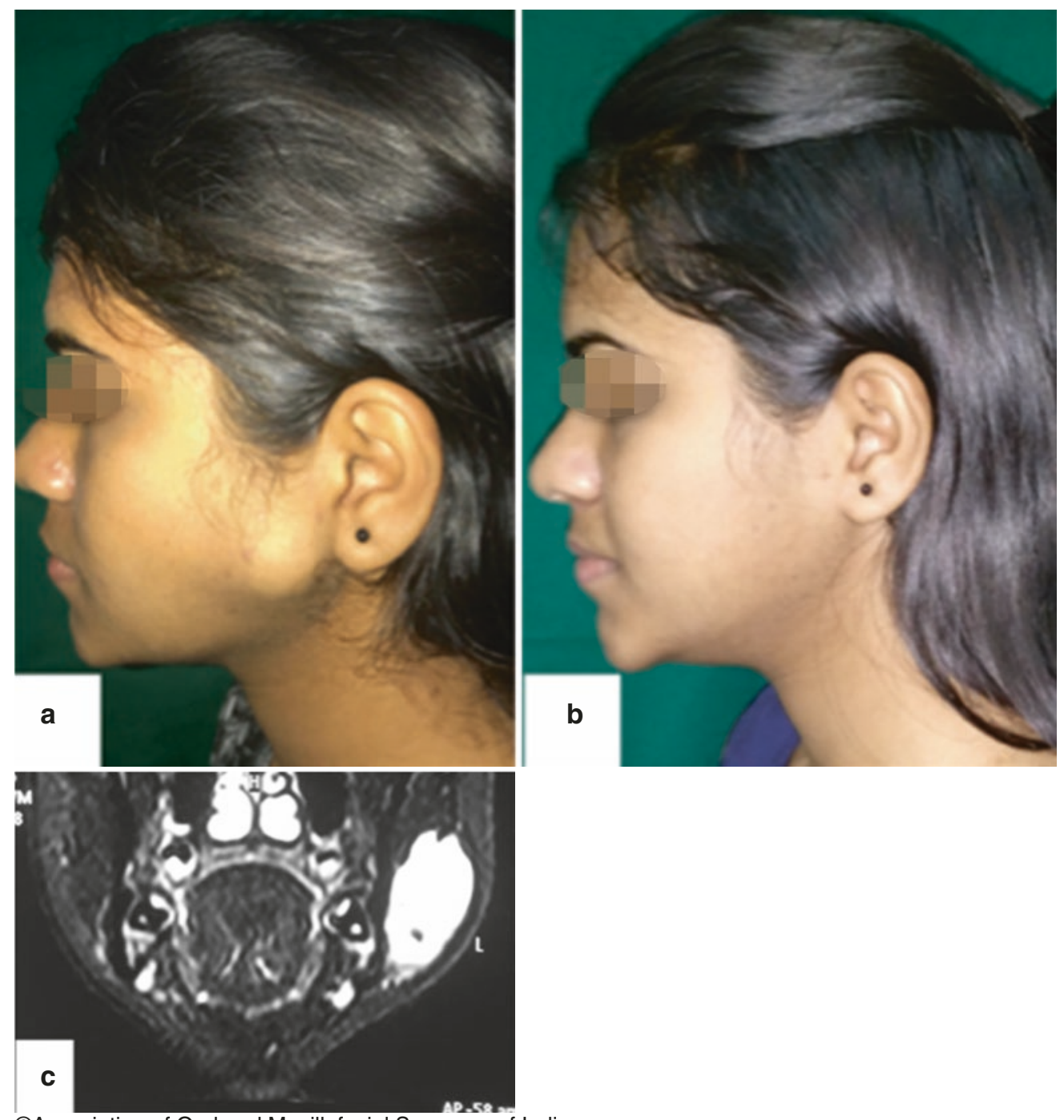

CAssociation of Oral and Maxillofacial Surgeons of India

Fig. 31.21 Venous malformation-Left cheek ((a) before sclerotherapy, (b) after sclerotherapy, (c) pre-treatment T2-weighted MRI image) 
ondary skeletal deformities, which are addressed due to functional or cosmetic reasons as necessary.

AVMs are the most challenging type of vascular malformations to manage due to their aggressive nature. They tend to cause progressive facial deformity and pose a significant systemic risk. They are high-flow lesions that typically demonstrate a nidus with arterial feeders, arteriovenous connections and enlarged veins. Schobinger's class III and IV demand aggressive management with combined embolisation, surgical excision and reconstructing the residual defect. Trans-arterial and trans-venous catheter angiography are commonly used for assessment, examination of the nidus and location of arterio-venous shunting. A few lesions can be controlled with frequent embolisation. The nidus must be treated to get control over the lesion. Catheter embolisation causes obliteration of the nidus in order to prevent a further increase in size and haemorrhagic complications. This can be either endovascular (Fig. 31.22) as used for large AVM's with aberrant feeders or percutaneous (Fig. 31.23) used for more superficial lesions. The feeders are sequentially embolised from distant to proximal feeders. Embolisation can be used for pre-surgical occlusion of feeder vessel on the same day of planned surgery to minimise intra-operative blood loss.

Commonly used embolic agents are:

Ethanol,

Cyanoacrylate (glue),

Coils, polyvinyl particles,

Onyx —a liquid ethylene vinyl alcohol copolymer.

Kaposiform Haemangioendotheliomas (KHEs) are treated with hematological agents such as vincristine, steroids or sirolimus. These systemic medications help in the resolution of KHE and associated KMP (Kasabach Merritt phenomenon). Surgical management of these lesions is usually not required but small lesions can be removed in toto with early intervention.

\subsection{Surgical Management}

Unlike in the past, most low- and high-flow vascular anomalies are amenable to surgical management by either excision or debulking. Smaller-sized lesions are almost always excised completely. In contrast, larger-sized lesions are mostly debulked and need multiple procedures. External carotid artery (ECA) control is used to have reasonable control before and during procedures involving high-flow lesions. This is partly because of collateral blood supply from the opposite side.

For simplicity, the author's own anatomical classification is followed as it makes the understanding of the surgical approaches and the rationale behind them more lucid and comprehensible. Also, the concept of 'Corset suturing' will be explained, which has been proved to be an asset in management of large low-flow vascular anomalies.

\subsubsection{Surgical Anatomy}

An understanding of the different layers and planes of dissection in the head and neck is important to approach and treat these vascular anomalies. The commonest areas involved in the head and neck are cheek, lower and upper lips, eyelids, pre-auricular, mandible, submandibular, submental, upper neck, posterior and lateral oropharynx. The glottis, sub-glottis and lower neck are less commonly involved. Lymphovascular malformations are seen occupying scalp and orbit commonly.

Layers of face from superficial to deep are-skin, subcutaneous tissue, SMAS layer, parotid fascia (pre-auricular)/ deep cervical fascia (sub-mandibular), salivary gland (parotid and sub-mandibular regions), muscle, periosteum and bone. The scalp has a loose areolar plane and all other tissues attached. The neck has vital structures like the carotid artery, jugular vein, spinal accessory nerve, cervical plexus and other muscles superficial and deep to them.

\subsubsection{Case Selection}

According to the author's classification, vascular malformations were categorised into five types based on their anatomy and depth of location in the head and neck. This is a good guide for selecting the type of surgical management and reconstruction.

- In type-I, superficial lesions require excision of skin or mucosa. Local or regional flaps have been used in reconstruction of the residual defect.

- Type-II, sub-mucosal lesions require complete excision after elevation of skin flaps.

- Type-III, lymphovenous malformations or venous malformations involve salivary glands and are excised along with the affected gland.

- Type-IV, intra-osseous lesions require excision with removal of involved bone and reconstruction of the residual defect as necessary. 

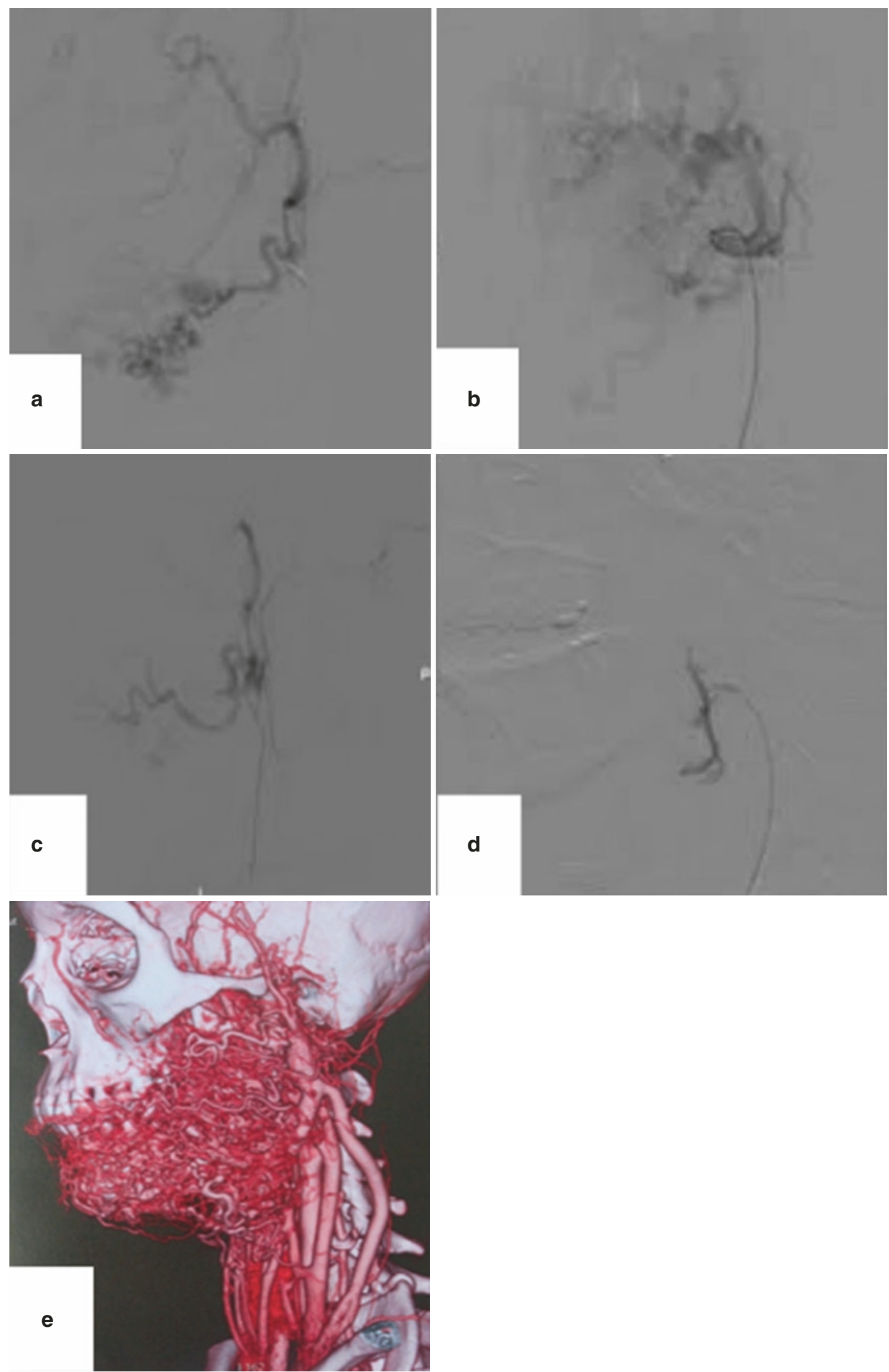

(C)Association of Oral and Maxillofacial Surgeons of India

Fig. 31.22 Sequential endovascular embolisation of left cheek AVM ((a-d) progressing blockage of blood supply to AVM, (e) 3D reconstructed view of the vascular network) 

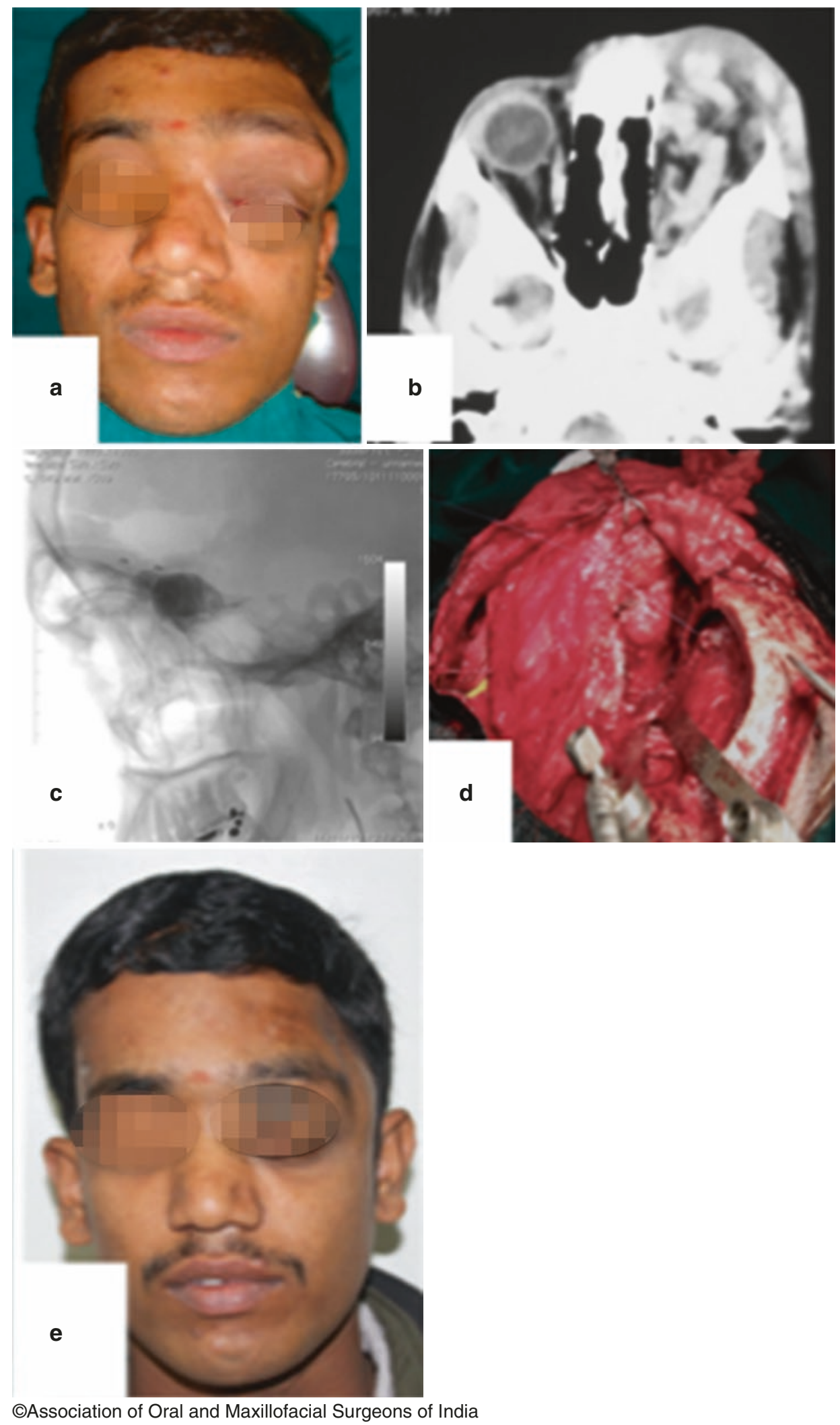

Fig. 31.23 AVM of left supra-orbit ((a) pre-operative, (b) CT with contrast, (c) percutaneous embolisation, (d) Surgical excision via haemicoronal approach, (e) post-operative) 
- Type-V lesions involve deep visceral spaces, such as the parapharyngeal or infra-temporal fossa and usually require mandibular access osteotomy for complete exposure and complete removal of the lesion.

The above procedures can demand either endovascular embolisation, intra-lesional embolisation or ECA control prior to attempting excision or debulking of these lesions.

\subsubsection{Technique of External Carotid Artery (ECA) Control (Fig. 31.24)}

The ECA of the involved side is exposed through a cervical incision, which often forms, part of the access for removal of the malformation. The sternocleidomastoid muscle is retracted posteriorly at the level of the greater cornu of the hyoid bone, exposing the carotid sheath. The external carotid distal to the carotid bifurcation is identified. The vessel is snared with a vascular sling passed through a rubber catheter. Gentle strangulation of the vessel can be accomplished by advancing the catheter. This additional compression of the vessel serves to reduce blood flow to the lesion. In demanding situations, the ECA can be ligated. Many times due to risk of collateral blood supply to these lesions, ECA control is an adjunct to achieving haemostasis along with aggressive local control.

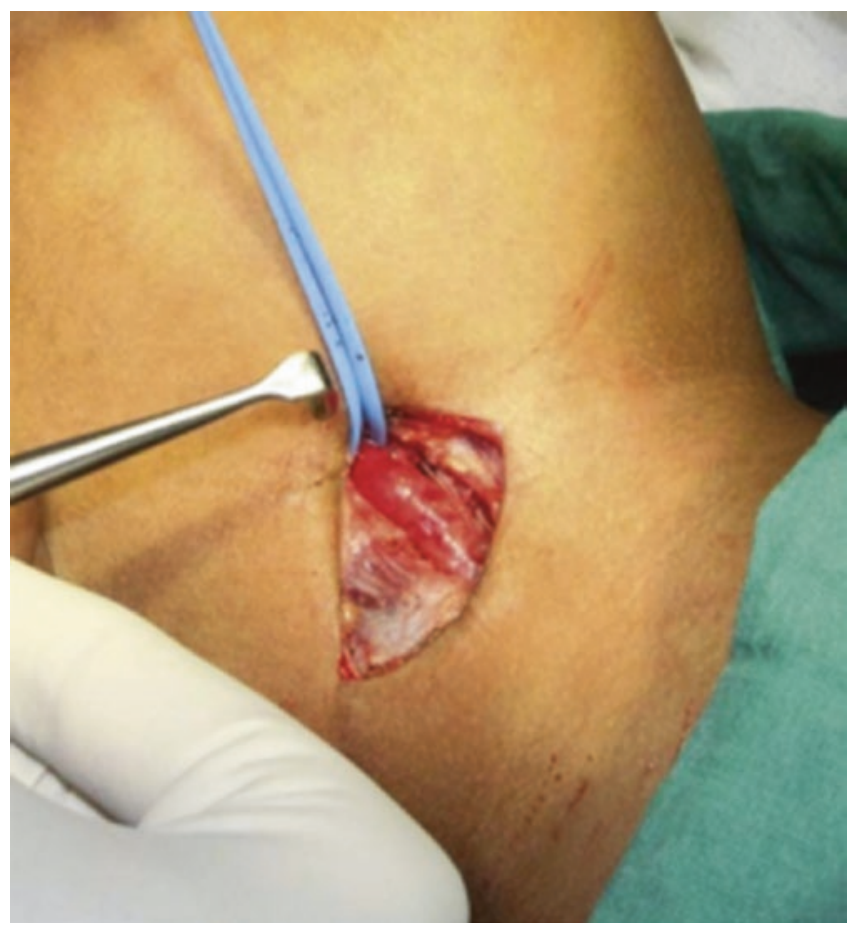

CAssociation of Oral and Maxillofacial Surgeons of India

Fig. 31.24 ECA control. Copyright: Authors own publications from IJOMS 2011

\subsubsection{Corset-Suturing Technique (Fig. 31.25)}

Corset suturing [26] is a proven technique in management of large low-flow venous malformations of head and neck, especially in lesions where complete excision is not practically possible and also those in close proximity to important structures like airway, facial nerve, spinal accessory nerve, internal jugular vein and in medically compromised individuals.

'Corset', is a garment worn to hold and train the torsoin to a desired shape for aesthetic or orthopaedic purposes. The procedure employed is raising a flap in the sub-SMAS or sub-cutaneous plane depending upon the type of lesion followed by placement of a bioresorbable suture (polydiaxanone) that runs in a continuous vertical looping fashion from sub-cutaneous to deep layer and from one end to another, incorporating the lesion within the suture. The suturing is advanced at regular and equidistant intervals to involve the bulk of lesion resulting in compression of the vascular spaces and causing obstruction of the afferent and efferent vessels. This reduces the risk of bleeding, swelling and size of lesion. The blood supply gets interrupted due to obstruction of afferent vessels. In large lesions, this suturing should be done parallel to each other covering the whole lesion from superior to inferior and medial to lateral, which would occlude the regional vascular channels, interrupting and obstructing the blood circulation in the tumour. These sutures must be tightened cautiously, slowly and progressively to achieve gradual and complete strangulation of vascular channels until complete closure of their lumen is assured. This procedure decompresses the lesion completely and reduces the risk of post-operative haemorrhage. The excess skin flap is excised, drains are secured followed by primary closure. The final scar is fairly acceptable, as all incisions are originally placed within the skin tension lines.

\subsubsection{Approaches and Excision/Debulking}

Superficial Type-I (Fig. 31.7) lesions mostly derive from the reticular dermis and is treated with direct excision and closure or local-flap reconstruction. Care is taken to place incisions along the skin tension lines of the face and neck to avoid unaesthetic results. It is challenging to select these lines in young individuals and every attempt is made to lay these incisions on prominent skin creases like nasolabial, mentolabial, pre-auricular and lower skin crease of neck.

Type-II (Fig. 31.8) lesions are approached by raising skin flaps using the following incisions, commonly-preauricular with either neck skin crease extension or temporal extension, neck crease incision alone, nasolabial skin crease incision, mid-face Weber-fergusson incision and coronal approach. Every attempt is made to maintain a sub-SMAS 

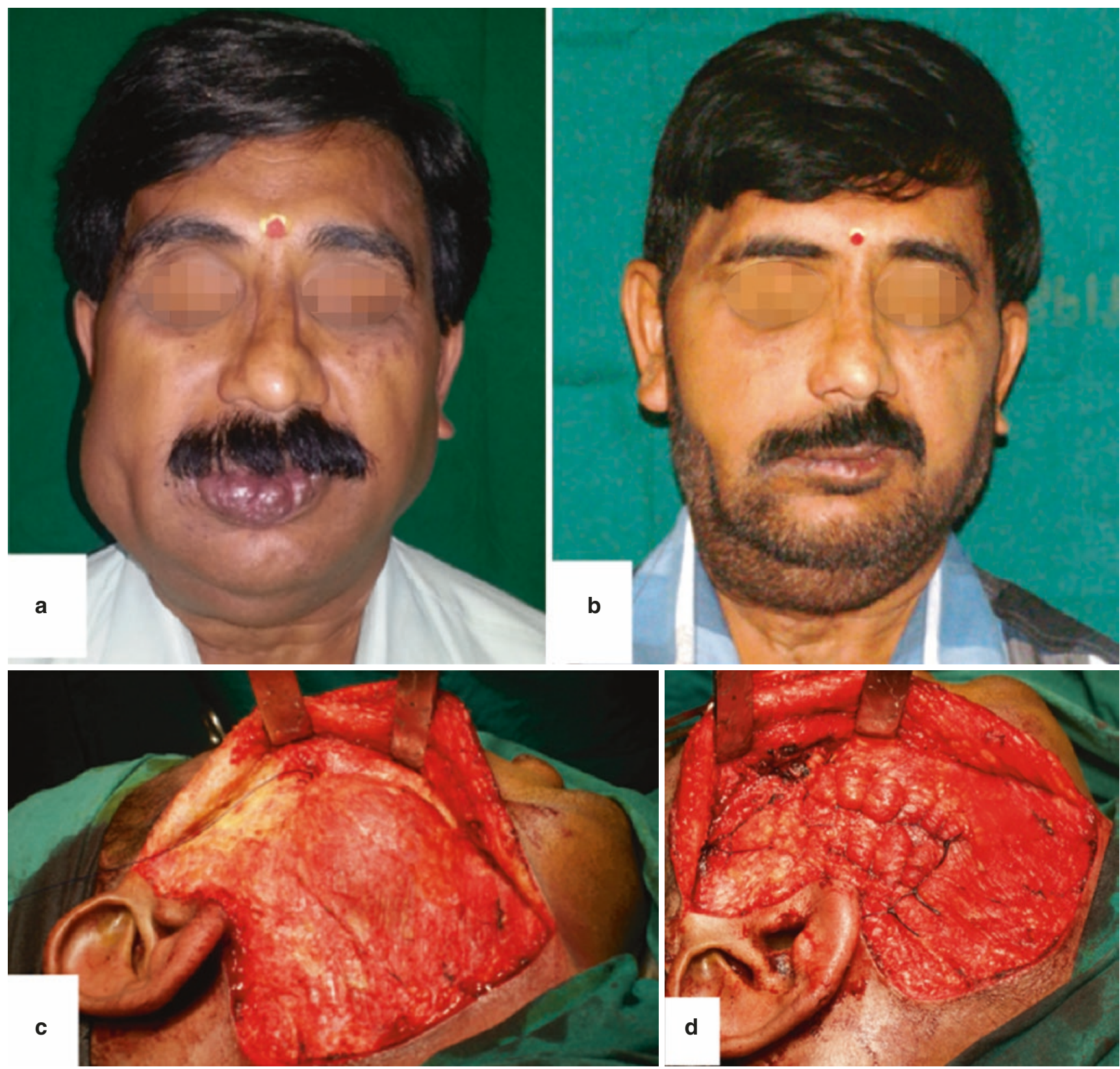

CAssociation of Oral and Maxillofacial Surgeons of India

Fig. 31.25 Venous malformation right face, lower lip ((a) pre-operative, (b) post-operative, (c) lesion exposure and (d) corset suturing of lesion). (Fig. 31.25 a,b,d - copyright authors own publication IJOMS 2018)

plane but vascular anomalies being composite in nature can demand modifications. There is always a risk of thinning the skin flap excessively and care should be taken to avoid button-holing and avoiding avascular necrosis. The lesion is excised completely or debulked depending on the size. Corseting is used for large low-flow malformations as described above.

Tongue lesions are mostly excised in toto or debulked in a $\mathrm{V}$ shaped fashion to achieve primary closure.
Type-III (Fig. 31.9) lesions are approached the same way as Type-II. Being deeper in nature, the gland is sacrificed with some risk of permanent facial nerve damage. Use of 'corseting' in these cases has shown good results with complete recovery of facial nerve weakness over a period of 1 year.

Type-IV (Fig. 31.10) lesions like other types are rarely seen on their own and are usually in combination with Type I, II or V. These lesions are treated with curettage or segmen- 
Algorithm 31.2

Management of Vascular malformations

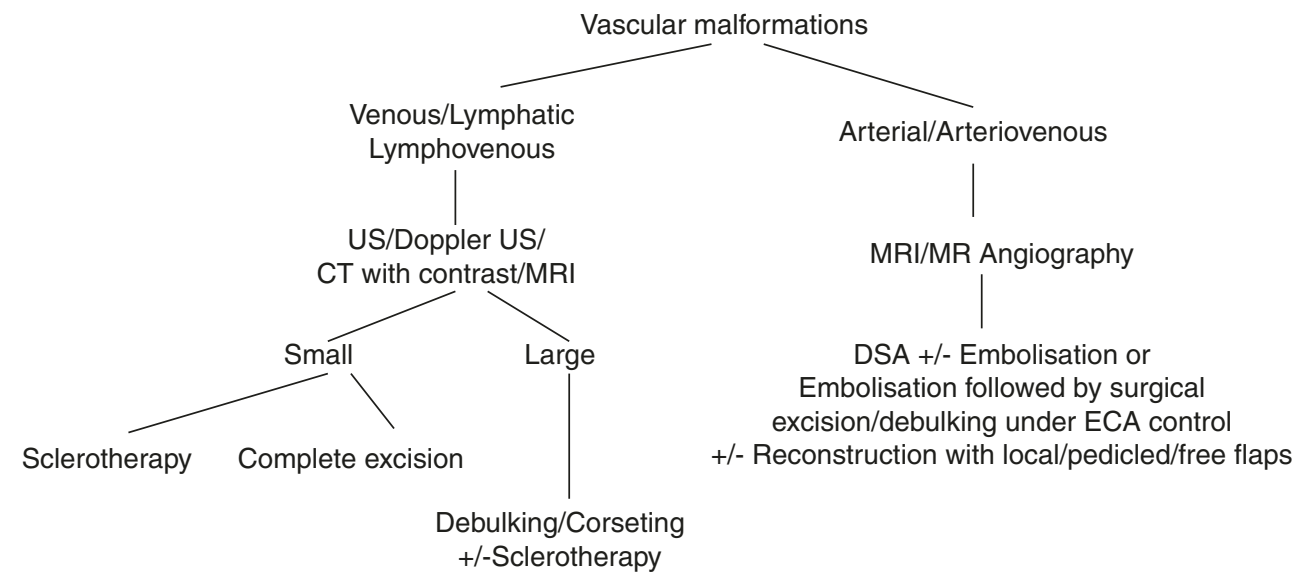

tal resection of bone followed by reconstruction (Fig. 31.13). There are reports of extra-corporeal curettage of segmentally resected lesions and re-fixation to maintain bone continuity.

Type-V (Fig. 31.11) lesions commonly require access to osteotomies like mandibulotomy, segmental or complete Lefort-I, rhinotomy or zygomatic swing osteotomies to gain adequate access. The lesions are uncapsulated and rarely excised completely but improve the quality of life and reduce risk of mortality due to airway obstruction and haemorrhage. In the authors' experience, use of corseting has proven to be beneficial in these cases.

Excess skin flap is always excised to give a near normal appearance. Use of an adequate number of drains and meticulous haemostatic closure is imperative to achieve acceptable and aesthetic results.

Most large lesions require further excision and debulking procedures as the age advances until growth is achieved. Large low-flow lesions have potential to be excised completely secondarily, following prior corset suturing.

Algorithm 31.2 summarises the management of vascular malformations.

\subsection{Complications}

Vascular lesions can have complications ranging from none (like in haemangiomas) to bleeding, ulcerations and infection. Superficial lesions and ulcerations benefit with the use of pulsed-dye laser. Bleeding can usually be managed with compression dressings.

Large venous and lymphatic malformations can cause local swelling, pressure effects on trachea and oesophagus, pain and infection, demanding immediate treatment like embolisation or surgical debulking along with control of airway and infection.
The two common complications of LMs are bleeding within the lesion and infection. Bleeding can be seen spontaneously or as a result of trauma. This further causes immediate and painful enlargement of the lesion with associated ecchymosis. Analgesia and observation usually suffice for symptomatic management. Prophylactic antibiotics can be given in the case of profuse bleeding. Long-term intravenous broad spectrum antibiotics may be necessary covering pathogens of head and neck, especially in high-risk patients. Haemorrhage and infection can sometimes transform a macro-cystic lesion into a micro-cystic type with associated scarring. LMs are known to increase in size in the presence of a viral or bacterial infection. This is usually selflimiting and thought to be due to changes in the lymphatic flow. Bacterial superinfections can be fatal causing ascending cellulitis and septicaemia. Any infection in cervicofacial LMs can cause obstruction of the upper airway and oesophagus causing dyspnea and dysphagia.

Incompletely treated AVMs tend to recur and continue to grow. They should not be underestimated.

\subsection{Recent Advances}

Micro-cystic lymphatic malformations have always been challenging cases to be treat, especially involving extra- and intracranial areas of head and neck. Currently available treatments have limited effectiveness and high risk of complications. Techniques using lymphography and idiocyanine green have been used to locate the exact location of afferent and efferent lymphatic flow and performing a lymphatic-venous anastomosis has been described in treating these lesions [27].

Vascular-disrupting agents (VDA's) [28] are a group of 'vascular targeting' agents that show selective activity against tumour vascular networks, causing severe obstruc- 
tion in their blood flow and subsequent necrosis. These have been investigated for a long time but haven't yet actively been used in the treatment of vascular lesions of the head and neck. Micro-tubule-depolymerising agents are the largest group of small molecular weight VDAs, which include lead compound disodium combretastatin A-4 3-O-phosphate (CA-4-P) [28], and are under clinical development for cancer. VDAs can also interfere with angiogenesis and can be potentially used as novel drugs for the treatment of conditions with excessive angiogenesis, in addition to cancer.

$3 \mathrm{D}$ remodelling and bioprinting of areas affected by vascular anomalies with their feeder vessels are under study, for training and familiarising one with possible complications during procedures like embolisation and surgery.

\subsection{Conclusion}

Vascular anomalies are a diverse group of lesions requiring knowledge and skill to identify, accurately diagnose and treat adequately. Most of these lesions present as a complex problem with a combination of different types and other systemic complicating features. This demands a multi-disciplinary team comprising maxillofacial surgeon, vascular surgeon, pediatrician, reconstructive surgeon, anaesthetist and speech and language therapist with extensive training, understanding and experience to tailor an appropriate treatment plan. Selection of sclerosants should be with caution to minimise their side effects. Surgery has an important role in achieving quicker and long-term stable results in most cases.

\section{References}

1. Nair SC, Spencer NJ, Nayak KP, Balasubramaniam K. Surgical management of vascular lesions of the head and neck: a review of 115 cases. Int J Oral Maxillofac Surg. 2011;40:577-83.

2. Mulliken JB, Young AE. Vascular birthmarks. Hemangiomas and malformations. Philadelphia: Saunders; 1988.

3. Brouillard P, Vikkula M. Vascular malformations: localized defects in vascular morphogenesis. Clin Genet. 2003;63:340.

4. Lohela M, Bry M, Tammela T, et al. VEGFs and receptors involved in angiogenesis versus lymphangiogenesis. Curr Opin Cell Biol. 2009;21:154.

5. Boon LM, Ballieux F, Vikkula M. Pathogenesis of vascular anomalies. Clin Plast Surg. 2011;38:7-19.

6. Richter GT, Friedman AB. Hemangiomas and vascular malformations: current theory and management. Int $\mathrm{J}$ Pediatr 2012;2012:645678
7. Marler JJ, John B. Mulliken current management of hemangiomas and vascular malformations. Clinic Plast Surg. 2005;32:99-116.

8. Takahashi K, Mulliken JB, Kozakewich HP, Rogers RA, Folkman J, Ezekowitz RA. Cellular markers that distinguish the phases of hemangioma during infancy and childhood. J Clin Invest. 1994;93:2357-64.

9. Eerola LMB, Watanabe S, Grynberg H, Mulliken JB, Vikkula M. Locus for susceptibility for familial capillary malformation ("port-wine stain") maps to 5q. Eur J Hum Genet. 2002;10(6):375-80.

10. Pavlov KA, Dubova EA, Shchyogolev AI, Mishnyov OD. Expression of growth factors in endotheliocytes in vascular malformations. Bull Exp Biol Med. 2009;147(3):366-70.

11. Corti P, Young S, Chen CY, et al. Interaction between alk1 and blood flow in the development of arteriovenous malfor- mations. Development. 2011;138(8):1573-82.

12. Kim H, Su H, Weinsheimer S, Pawlikowska L, Young WL. Brain arteriovenous malformation pathogenesis: a response-to-injury paradigm. Acta Neurochir Suppl. 2011;111:83-92.

13. Mulliken J, Glowacki J. Hemangiomas and vascular malformations in infants and children: a classification based on endothelial charecteristics. Plast Reconstr Surg. 1982;69(3):412-20.

14. Ethunandan M, Mellor TK. Hemangiomas and vascular malformations of the maxillofacial region - review. Br J Oral Maxillofac Surg. 2006;44:263-72.

15. ISSVA Classification of Vascular Anomalies (2018 International Society for the Study of Vascular Anomalies Available at "issva. org/classification".

16. Johnson AB, Richter GT. Vascular anomalies. Clin Perinatol. 2018;45(4):737-49.

17. Kilcline C, Frieden IJ. Infantile hemangiomas: how common are they? A systematic review of the medical literature. Pediatr Dermatol. 2008;25(2):168-73.

18. Mohan RPS, Dhillon M, Gill N. Intraoral venous malformation with phleboliths. Saudi Dent J. 2011;23:161-163).

19. de Serres LM, Sie KC, Richardson MA. Lymphatic malformations of the head and neck. A proposal for staging. Arch Otolaryngol Head Neck Surg. 1995;121(5):577-82.

20. Kohout MP, Hansen M, Pribaz JJ, Mulliken JB. Arteriovenous malformations of the head and neck: natural history and management. Plast Reconstr Surg. 1998;102(3):643-54.

21. Croteau SE, Liang MG, Kozakewich HP, et al. Kaposiform hemangioendothelioma: atypical features and risks of Kasabach-Merritt phenomenon in 107 referrals. J Pediatr. 2013;162(1):142-7.

22. Steinklein JM, Shatzkes DR. Imaging of vascular lesions of head and neck. Otolaryngol Clin N Am. 2018;51:55-76.

23. Baek HJ, Hong JP, Choi JW, Suh DC. Direct percutaneous alcohol sclerotherapy for venous malformations of head and neck region without fluoroscopic guidance: technical consideration and outcome. Neurointervention. 2011;6:84-8.

24. Hoff SR, Rastatter JC, Richter GT. Head and neck vascular lesions. Otolaryngol Clin N Am. 2015;48:29-45.

25. Horbach SER, Lokhorst MM, Saeed P, de Goüyon Matignon de Pontouraude CMF, Rothová A, van der Horst CMAM. Sclerotherapy for low-flow vascular malformations of the head and neck: A systematic review of sclerosing agents. J Plast Reconstr Aesthet Surg. 2016;69:295-304

26. Nair SC, Chawla JP, Shroff SS, Kumar B, Shah A. Corseting: a new technique for the management of diffuse venous malforma- 
tions in the head and neck region. Int J Oral Maxillofac Surg. 2018;47(12):1534-40.

27. Kato M, Watanabe S, Iida T, Watanabe A, Megumi F. Peri-orbital lymphangioma treated by lymphatic-venous anastomosis with indocyanine green lymphography analysis. J Pediatr Surg Case Rep. 2017;23:9e14.
28. Kanthou C, Tozer GM. Microtubule depolymerizing vascular disrupting agents: novel therapeutic agents for oncology and other pathologies. Int J Exp Pathol. 2009;90:284-94.

Open Access This chapter is licensed under the terms of the Creative Commons Attribution 4.0 International License (http://creativecommons. org/licenses/by/4.0/), which permits use, sharing, adaptation, distribution and reproduction in any medium or format, as long as you give appropriate credit to the original author(s) and the source, provide a link to the Creative Commons license and indicate if changes were made.

The images or other third party material in this chapter are included in the chapter's Creative Commons license, unless indicated otherwise in a credit line to the material. If material is not included in the chapter's Creative Commons license and your intended use is not permitted by statutory regulation or exceeds the permitted use, you will need to obtain permission directly from the copyright holder. 